\title{
Transport, properties, and life cycles of mesoscale eddies in the eastern tropical South Pacific
}

\author{
Rena Czeschel $^{1}$, Florian Schütte ${ }^{1}$, Robert A. Weller ${ }^{2}$, and Lothar Stramma ${ }^{1}$ \\ ${ }^{1}$ GEOMAR Helmholtz Centre for Ocean Research Kiel, Düsternbrooker Weg 20, 24105 Kiel, Germany \\ ${ }^{2}$ Woods Hole Oceanographic Institution (WHOI), 266 Woods Hole Rd, Woods Hole, MA 02543, USA \\ Correspondence: Rena Czeschel (rczeschel@geomar.de)
}

Received: 15 January 2018 - Discussion started: 31 January 2018

Revised: 14 May 2018 - Accepted: 9 July 2018 - Published: 31 July 2018

\begin{abstract}
The influence of mesoscale eddies on the flow field and the water masses, especially the oxygen distribution of the eastern tropical South Pacific, is investigated from a mooring, float, and satellite data set. Two anticyclonic (ACE1/2), one mode-water (MWE), and one cyclonic eddy (CE) are identified and followed in detail with satellite data on their westward transition with velocities of 3.2 to $6.0 \mathrm{~cm} \mathrm{~s}^{-1}$ from their generation region, the shelf of the Peruvian and Chilean upwelling regime, across the Stratus Ocean Reference Station (ORS; $\sim 20^{\circ} \mathrm{S}, 85^{\circ} \mathrm{W}$ ) to their decaying region far west in the oligotrophic open ocean. The ORS is located in the transition zone between the oxygen minimum zone and the well oxygenated South Pacific subtropical gyre. Velocity, hydrographic, and oxygen measurements at the mooring show the impact of eddies on the weak flow region of the eastern tropical South Pacific. Strong anomalies are related to the passage of eddies and are not associated with a seasonal signal in the open ocean. The mass transport of the four observed eddies across $85^{\circ} \mathrm{W}$ is between 1.1 and $1.8 \mathrm{~Sv}$. The eddy type-dependent available heat, salt, and oxygen anomalies are $8.1 \times 10^{18} \mathrm{~J}$ (ACE2), $1.0 \times 10^{18} \mathrm{~J}$ (MWE), and $-8.9 \times 10^{18} \mathrm{~J}(\mathrm{CE})$ for heat; $25.2 \times 10^{10} \mathrm{~kg}$ (ACE2), $-3.1 \times 10^{10} \mathrm{~kg}$ (MWE), and $-41.5 \times 10^{10} \mathrm{~kg}$ (CE) for salt; and $-3.6 \times 10^{16} \mu \mathrm{mol}$ (ACE2), $-3.5 \times 10^{16} \mu \mathrm{mol}$ (MWE), and $-6.5 \times 10^{16} \mu \mathrm{mol}(\mathrm{CE})$ for oxygen showing a strong imbalance between anticyclones and cyclones for salt transports probably due to seasonal variability in water mass properties in the formation region of the eddies. Heat, salt, and oxygen fluxes out of the coastal region across the ORS region in the oligotrophic open South Pacific are estimated based on these eddy anomalies and on eddy statistics (gained out of 23 years of satellite data). Furthermore, four profiling
\end{abstract}

floats were trapped in the ACE2 during its westward propagation between the formation region and the open ocean, which allows for conclusions on lateral mixing of water mass properties with time between the core of the eddy and the surrounding water. The strongest lateral mixing was found between the seasonal thermocline and the eddy core during the first half of the eddy lifetime.

\section{Introduction}

The eastern tropical South Pacific (ETSP) containing the Peruvian upwelling regime, which is one of the four major eastern boundary upwelling systems, shows pronounced mesoscale and sub-mesoscale variability (e.g. Capet et al., 2008; McWilliams et al., 2009; Chaigneau et al., 2011). Mesoscale variability in the ocean occurs as linear Rossby waves and as nonlinear vortices or eddies. During the last two decades eddies have been recognized to play an important role in the vertical and horizontal transport of momentum, heat, mass, and chemical constituents of seawater (e.g. Chelton et al., 2007; Klein and Lapeyre, 2009) and therefore contribute to the large-scale water mass distribution. Especially in upwelling areas, eddies have been identified as major agents for the exchange between coastal waters and the open ocean (e.g. Chaigneau et al., 2008; Pegliasco et al., 2015; Schütte et al., 2016a). At least three types of eddies have been identified: cyclonic, anticyclonic, and anticyclonic mode-water eddies (e.g. McWilliams, 1985; D'Asaro, 1988; McGillicuddy Jr. et al., 2007), as well as a transition from cyclonic eddies to "cyclonic thinnies" to exist throughout the world ocean (McGillicuddy Jr., 2015). Usually, isopycnals 

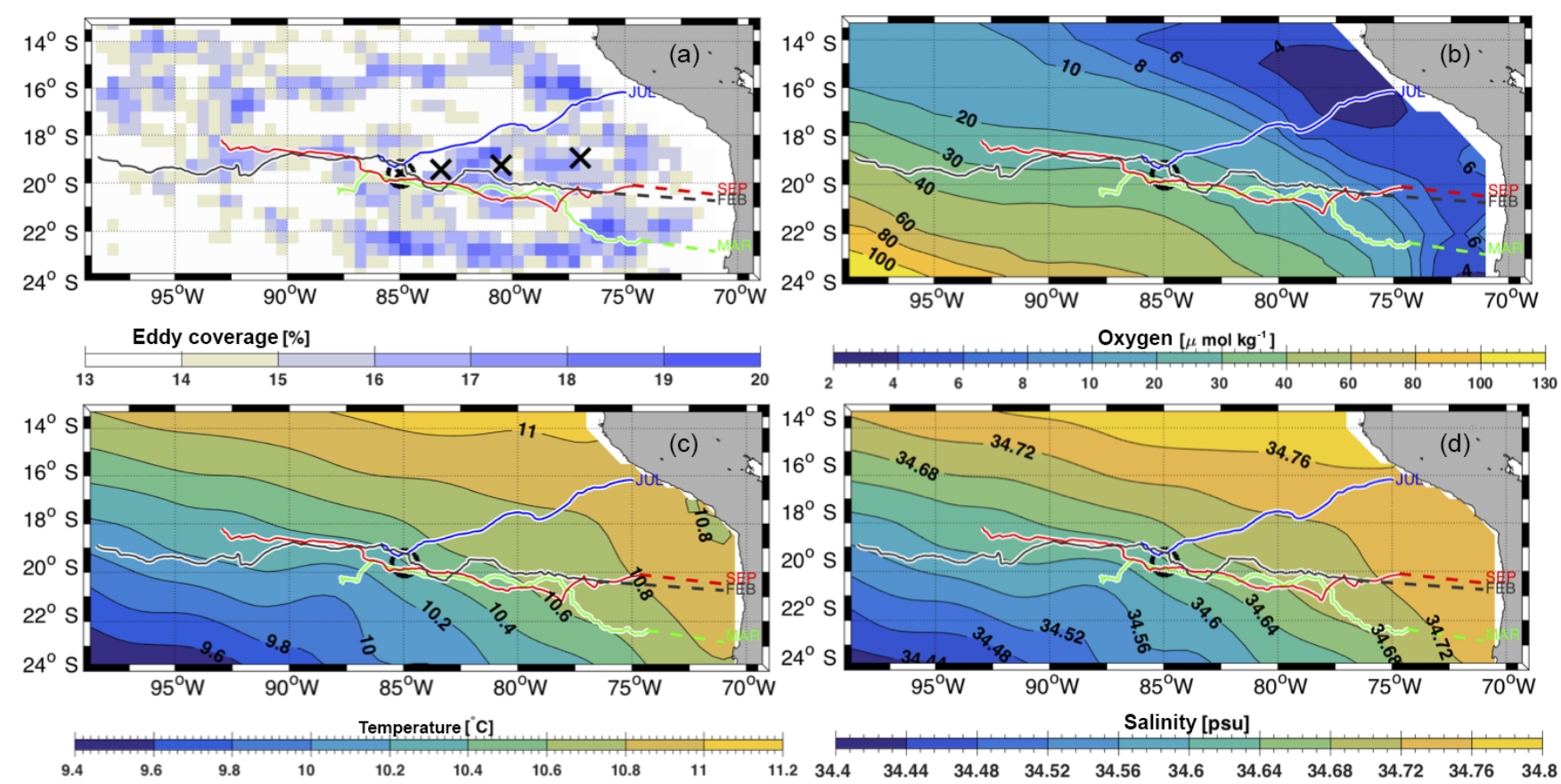

Figure 1. (a) Percentage of eddy coverage determined from Aviso sea level anomaly (SLA) during the period from 1993 to 2015 . The mean distribution of (b) oxygen, (c) temperature, and (d) salinity on density surface $26.6 \mathrm{~kg} \mathrm{~m}^{-3}$ derived from the monthly isopycnal and mixedlayer ocean climatology (MIMOC; Schmidtko et al., 2013). The black $\times$ 's show the location of the float deployments, the westernmost $\times$ with the circle is also the location of the Stratus mooring. The green, red, and black lines represent trajectories of the anticyclones (ACE1, ACE2) and the anticyclonic mode-water eddy (MWE), whereas the blue line is associated with the trajectory of a cyclone (CE). Dashed lines show the extrapolated tracks to the formation regions and the estimated time of formation. All of these eddies have crossed close to the mooring position and are examined in more detail.

in anticyclonic eddies are depressed for the entire vertical extent of the eddy, while in mode-water eddies a thick lens of water deepens the main thermocline while shoaling the seasonal thermocline (McGillicuddy Jr. et al., 2007). Modewater eddies are also often referred to as intrathermocline eddies (ITEs; Hormazabal et al., 2013). Cyclones dome both the seasonal and main pycnocline.

Several analyses of the mean eddy properties offshore of the Peruvian coast have been conducted in the last decade and found the largest eddy frequency in the ETSP off Chimbote $\left(\sim 9^{\circ} \mathrm{S}\right)$ and south of San Juan $\left(15^{\circ} \mathrm{S}\right)$ (e.g. Chaigneau et al., 2008, or Fig. 1a). Using a combination of Argo float profiles and satellite data, the three-dimensional mean eddy structure of the eastern South Pacific was described for the temperature, salinity, density, and geostrophic velocity field of cyclones as well as anticyclones (Chaigneau et al., 2011). However, a distinction in "regular" anticyclones and anticyclonic mode-water eddies is still pending in the ETSP. From recent findings (Stramma et al., 2013; Schütte et al., 2016a, b) it seems to be mandatory to distinguish between these two eddy types as they strongly differ in their efficiency to transport conservative tracers, especially in upwelling areas. In addition it is observed that the different eddy types influence non-conservative tracers, like dissolved oxygen, in different ways within their isolated eddy cores. Especially cyclones and anticyclonic mode-water eddies have been reported to create an isolated biosphere, which greatly differs from the biosphere present in the surrounding areas (Altabet et al., 2012; Löscher et al., 2015). In these eddy cores the oxygen concentration can decrease with time (Fiedler et al., 2016; Schütte et al., 2016b). In wide areas of the world ocean eddies with an open-ocean low-oxygen core are observed (e.g. North Pacific: Lukas and Santiano-Mandujano, 2001; South Pacific: Stramma et al., 2013; tropical North Atlantic: Karstensen et al., 2015). These low-oxygen eddies have strong impacts on sensible metazoan communities and marine life (Hauss et al., 2016). Anammox is the leading nitrogen loss process in ETSP eddies whereas denitrification was undetectable (Callbeck et al., 2017), while denitrification appears only patchy in the ETSP (Dalsgaard et al., 2012). Low-oxygen eddies release a strong negative oxygen anomaly during their decay, which may influence the largescale oxygen distribution (Schütte et al., 2016b).

The following paper includes an analysis of the three different eddy types and their impact on the water masses and oxygen distribution in the ETSP and is based on the Stratus Ocean Reference Station (ORS) mooring. The Stratus mooring is located at $\sim 20^{\circ} \mathrm{S}, 85^{\circ} \mathrm{W}$ in the transition zone between the oxygen minimum zone (OMZ) and the well oxygenated subtropical gyre (e.g. Tsuchiya and Talley, 1998). 
Eddy analyses were also done in the past at the Stratus mooring, where a snapshot of a strong anticyclonic mode-water eddy was observed in March/April 2012 (Stramma et al., 2014). In this paper we investigate in more detail the mooring period March 2014 to April 2015 and set a focus on the isolation and development of an eddy core during its isolated lifetime. We intensively followed eddies of each kind (two "regular" anticyclones, one anticyclonic mode-water eddy and one cyclone) which crossed the Stratus mooring position, from their formation areas near the coast to their decay eastwards of the Stratus mooring (Fig. 1). During their lifetime one of these eddies was also partly sampled by several profiling floats equipped with oxygen sensors which were deployed in March 2014 within the eddies (Fig. 1).

In general, the large-scale oxygen distribution in the ETSP is dominated by a strong OMZ at depths of $100-900 \mathrm{~m}$ with minimum oxygen values at about $350 \mathrm{~m}$ depth $\left(\sigma_{\theta}=\right.$ $26.8 \mathrm{~kg} \mathrm{~m}^{-3}$ ) and suboxic conditions of $<4.5 \mu \mathrm{mol} \mathrm{kg}{ }^{-1}$ off Peru (e.g. Karstensen et al., 2008; Paulmier and Ruiz-Pino, 2009 , or Fig. 1b). In the OMZ the oxycline of $60 \mu \mathrm{mol} \mathrm{kg}-1$ extends along the South American coast from $35^{\circ} \mathrm{S}$ to the Equator where it reaches westward to nearly $160^{\circ} \mathrm{E}$ (Llanillo et al., 2018).

In the ETSP the zonal tropical current bands supply oxygen-rich water $\left(\mathrm{O}_{2}\right)$ to the $\mathrm{OMZ}$ (Stramma et al., 2010). In contrast, the mid-depth circulation in the eastern South Pacific Ocean is sluggish in the region of the OMZ. As the mean currents are weak, eddy variability strongly influences the flow and ultimately supplies oxygen-poor water to the OMZ (Czeschel et al., 2011). A rough estimate of the oxygen budget of the eastern tropical Pacific Ocean (Stramma et al., 2010) was used to estimate $22 \%$ by vertical mixing, $33 \%$ by advection, and the largest component of $45 \%$ by eddy mixing (Brandt et al., 2015).

The mean upper ocean circulation of the ETSP is relatively complex exhibiting several surface and subsurface currents. It is described to be composed of the South Pacific subtropical gyre with the north-eastern current band shown to be located south of 10 to $15^{\circ} \mathrm{S}$ called the Humboldt Current, South Equatorial Current, Oceanic Chile-Peru Current, or Peru Oceanic Current (e.g. Kessler, 2006; Ayón et al., 2008), a set of several zonal current bands between the subtropical gyre and the Equator (e.g. Kessler, 2006; Czeschel et al., 2015), as well as poleward and equatorward current bands near the South American continent (e.g. Chaigneau et al., 2013). The shipboard zonal velocity component along about $86^{\circ} \mathrm{W}$ composed of three acoustic Doppler current profiler (ADCP) surveys showed larger regions with westward then eastward flow between 13 and $22^{\circ} \mathrm{S}$ (Brandt et al., 2015), although influenced by eddy features in ADCP measurements in November 2012 (Czeschel et al., 2015).

In general most of the eddies in the ETSP propagate westward originating from eddy generation hotspots near the coast following different eddy corridors (Fig. 1a). Coastal water properties are captured within the eddy cores and trans- ported on their way into the open ocean across several oxygen, temperature, and salinity gradients (Fig. 1b, c, d). The coastal water mass properties differ, due to the upwelling, which is strongest in the austral winter months from a seasonal cycle. The upwelled water near the coast identified as Equatorial Subsurface Water (ESSW; e.g. Thomsen et al., 2016) is colder, fresher, and less oxygenated in austral winter than in austral summer.

This paper describes the temperature, salinity, and oxygen anomaly of the different eddy types in the ETSP and their efficiency to dissipate the existing gradients. Of special interest is the eddy type-dependent isolation of the eddy cores during different eddy life stages. Knowledge about the initial eddy-core conditions near the generation areas, measurements during the mid-age of the eddy due to Argo floats, and measurements of the Stratus mooring at the end of the eddy lifetime allows us to investigate the fluxes associated with the eddies and the lateral mixing from the eddy-core water masses with its surrounding waters.

\section{Data sets}

\subsection{Stratus mooring}

Since October 2000 the Stratus mooring has been maintained at about $20^{\circ} \mathrm{S}, 85.5^{\circ} \mathrm{W}$ mainly to collect an accurate record of surface meteorology and air-sea fluxes of heat, freshwater, and momentum (Colbo and Weller, 2009). In addition velocity, pressure, temperature, and conductivity sensors (for salinity computation) and 13 oxygen sensors were added to the mooring within the water column during the deployment period 8 March 2014 to 25 April 2015 at $19^{\circ} 37^{\prime} \mathrm{S}, 84^{\circ} 57^{\prime} \mathrm{W}$ (velocity sensors used in this paper were also added during the deployment period 6 April 2011 to 29 May 2012 at $\left.19^{\circ} 41^{\prime} \mathrm{S}, 85^{\circ} 34^{\prime} \mathrm{W}\right)$. The depth distribution of the different measuring devices for the 2014 to 2015 deployment period are given in Table S1 and Fig. S1 in the Supplement (depth distribution of the velocity sensors for the 2011 to 2012 deployment period are listed in Stramma et al., 2014). Annual mean velocity profiles were computed for the upper $600 \mathrm{~m}$ for the two Stratus mooring deployment periods 2011/2012 and 2014/2015 where oxygen measurements were conducted. To avoid influences of seasonal signals, only the period 10 to 9 April of the following year was computed and only instruments were used which recorded the velocity for the entire period. These mean velocity profiles can be compared with the October 2000 to December 2004 mean velocity components (Colbo and Weller, 2007).

From the 13 oxygen sensors added to the 2014/2015 mooring period (Supplement Table S1), 3 instruments recorded erroneous oxygen values, which could not be corrected after the recovery. The remaining 10 oxygen sensors consist of 8 Aanderaa oxygen sensors in SeaGuard instruments, which were used with the manufacturers calibration (accu- 
racy $<8 \mu \mathrm{mol} \mathrm{kg}{ }^{-1}$ or $5 \%$ ) and 2 oxygen loggers, which received an additional lab calibration. For the 15 MicroCats (pressure, temperature and salinity), a data calibration is done against shipboard CTD data during the service cruises (RV Ron Brown, RB 14-01, and RV Cabo de Hornos) and later by comparison with the data overlap with the previous mooring and by returning the instruments to Sea-Bird Scientific for laboratory calibration. The SeaGuard conductivity sensors in 107 and $350 \mathrm{~m}$ depth have an offset of -0.13 and $-0.18 \mathrm{psu}$, respectively.

\subsection{Satellite data}

Satellite-derived sea level anomaly (SLA) data provided by the Copernicus Marine and Environment Monitoring Service (CMEMS) were used to identify and track the different eddies passing the Stratus mooring and to document the position of the floats within the eddies. The delayed-time "all-satmerged" reference data set of SLA is used which is mapped on an $0.25^{\circ} \times 0.25^{\circ}$ Cartesian grid and has a temporal resolution of 1 day. The time period January 1993 to December 2015 was chosen for the SLA and the geostrophic velocity anomalies are also provided by CMEMS.

For sea surface temperature (SST) the "Microwave Infrared Fusion Sea Surface Temperature" from Remote Sensing System (http://www.remss.com/; REMSS, 2017) is used. The data consist of SST measurements of all operational microwave radiometer (TMI, AMSR-E, AMSR2, WindSat) and infrared SST measurements (Terra MODIS, Aqua MODIS). Considered here are daily data with $9 \mathrm{~km}$ resolution from January 2013 to December 2015.

For sea surface chlorophyll (Chl) the MODIS/Aqua Level 3 data product mapped on a $4 \mathrm{~km}$ grid available at http://oceancolor.gsfc.nasa.gov (last access: 18 June 2017) provided by NASA is used. The time period January 2013 to December 2015 with a daily resolution is chosen. Note that the $\mathrm{Chl}$ data are cloud dependent as they are measured via infrared light.

\subsection{Argo floats}

Seven profiling Argo floats with Aanderaa oxygen sensors were deployed in March 2014 at $19^{\circ} 36^{\prime} \mathrm{S}, 8^{\circ} 58^{\prime} \mathrm{W}$; $19^{\circ} 27^{\prime} \mathrm{S}, 83^{\circ} 01^{\prime} \mathrm{W} ; 19^{\circ} 15^{\prime} \mathrm{S}, 80^{\circ} 30^{\prime} \mathrm{W}$; and $18^{\circ} 58^{\prime} \mathrm{S}$, $76^{\circ} 59^{\prime} \mathrm{W}$. The deployment locations (Fig. 1a) were chosen to be close to anticyclonic or cyclonic eddies determined from SLA figures. The floats were deployed in pairs with drifting depth at 400 and 1000 dbar and cycling intervals of 10 days, except for $18^{\circ} 58^{\prime} \mathrm{S}, 76^{\circ} 59^{\prime} \mathrm{W}$ only one float was deployed at 400 dbar drifting depth. From those seven Argo floats, four floats remained for a longer period within eddies which later crossed the Stratus mooring and are therefore used in more detail for our calculations in the paper (the four Argo floats are: 6900527, 6900529, 6900530, and 6900532). Typically a full calibration of the oxygen sensors on the Argo floats is not available. The different manufactures of Argo float oxygen sensors specify their measurement error at least better than $8 \mu \mathrm{mol} \mathrm{kg} \mathrm{kg}^{-1}$ or $5 \%$. Additionally the Argo float profiles of temperature, salinity, and oxygen are compared and calibrated against the measurements of the Stratus mooring and against each other giving a relative accuracy.

\section{Methods}

From the Stratus mooring time series (from 8 March 2014 to 25 April 2015) of velocity, temperature, salinity, and oxygen, eddies of each type are identified and followed back and forward in time with the help of satellite data. The focus is set on one mode-water eddy (MWE), two anticyclonic eddies (ACE1, ACE2), and one cyclonic eddy (CE) as they are also sampled by Argo floats (including oxygen sensors).

\subsection{Heat, salt, and oxygen anomaly at the Stratus mooring}

Available heat, salt, and oxygen anomalies (AHA, ASA, and AOA) were calculated as described in Chaigneau et al. (2011) and Stramma et al. (2014). At the Stratus mooring, eddy core anomalies were estimated by the difference between the mean of temperature, salinity, and oxygen within the eddy boundaries and the background field estimated from the annual mean for the period 10 April 2014 to 9 April 2015. Eddy boundaries are determined for every depth by the mean of the maximum absolute values of the $90 \mathrm{~h}$ low-pass filtered southward and northward velocity. The mean westward propagation of the eddies estimated from SLA measurements is used to convert the time axis to a space axis leading to a mean radius. The vertical extent is defined as the depth of the coherent structure of the eddy, which is the ratio between the swirl velocity $U$ and the propagation velocity $c$ of the eddy. If $U / c>1$, the feature is nonlinear and maintains its coherent structure while propagating westward (Chelton et al., 2011). The swirl velocity is derived from the mean of the absolute values of the maximum $90 \mathrm{~h}$ low-pass filtered southward and northward velocity. Error bars for the horizontal eddy boundaries are computed using the mean of the maximum absolute values of the hourly-mean southward and northward velocities. As a result the swirl velocity increases and likewise the vertical extent of the eddies due to the ratio between swirl velocity $U$ and propagation velocity $c$. Nonetheless, the deviations of the horizontal boundaries of the eddy are small. The deviations of the radius are used to estimate the error for AHA, ASA, and AOA from uncertainties in the size of the eddies.

At the time when the mooring was deployed, part of the MWE had already passed the mooring. Assuming a symmetric eddy, the centre of the MWE passed the mooring on 8 March 2014 and fully passed the mooring until end of March 2014. The measurements of the eastern part of the eddy dur- 
ing that time span were mirrored to obtain the full coverage of the MWE.

\subsection{Determining properties of the MWE, ACE1/2, and CE conducted from satellite data}

The eddy shape is identified by analysing streamlines of the SLA-derived geostrophic flow around an eddy centre (high/low SLA). Often the eddy boundary is defined as the streamline with the strongest swirl velocity (for more information on such an eddy detection algorithm see Nencioli et al., 2010). For comparison of our results with the results of Chaigneau et al. (2011) we also use the boundary definition of the streamline with the strongest swirl velocity. Note that the identified areas are irregularly circular therefore the circle-equivalent area is used to estimate the eddy radius. Due to the resolution of the SLA data, the eddy radius must be at least $45 \mathrm{~km}$ to unambiguously state that the identified area is a coherent mesoscale eddy and not an artificial signal. Clearly identified individual eddies may have a smaller radius than $45 \mathrm{~km}$ to get tracked. Eddies are tracked forward and backward in time following the approach described by Schütte et al. (2016a). To estimate the percentage of eddy coverage in the ETSP, eddies are identified and tracked between 1993 and 2015. In the following it was counted how often a grid point $\left(0.5^{\circ} \times 0.5^{\circ}\right)$ was covered by an eddy structure. For the identification of eddy generation areas, every newly detected eddy closer than $600 \mathrm{~km}$ off the coast is counted in $1^{\circ} \times 1^{\circ}$ boxes. The sum of all these boxes is taken to compute the seasonal cycle of eddy generation. The Argo float profiles and the mooring time series are separated into data conducted within cyclones, anticyclones, and the "surrounding area" which is not associated with eddy-like structures also following the approach of Schütte et al. (2016a). In addition the relative position of the mooring or Argo float profile in relation to the eddy centre and eddy boundary could be computed.

Furthermore, the composites of the eddy surface signatures (SLA, SST, and Chl) consist of $150 \times 150 \mathrm{~km}$ snapshots around the identified eddy centres. To exclude largescale variations, the SST data are low-pass filtered (cut-off wavelength of $15^{\circ}$ longitude and $5^{\circ}$ latitude) and subtracted from the original data to preserve only the mesoscale variability (see Schütte et al., 2016a, for more details).

\section{Results}

\subsection{General eddy generation and its seasonal cycle in the ETSP}

In the ETSP, 5244 eddies (49\% cyclones; $51 \%$ anticyclones) are found between January 1993 and December 2015 (requirement: having a radius between 45 and $150 \mathrm{~km}$ and visible for more than 7 days). Both types of eddies have an average radius of about $70 \mathrm{~km}$ and on average $15 \%$ of the
ETSP are covered everyday with eddies (Fig. 1a). Most of the eddies are generated close to the Peruvian or Chilean coast, where large horizontal/vertical shears exist in an otherwise quiescent region. In almost entire agreement with Chaigneau et al. (2008), hotspot locations of eddy generation are near the coast around $10^{\circ} \mathrm{S}$ and between 16 to $22^{\circ} \mathrm{S}$ (Fig. 2a, b). The four eddies (MWE, CE, ACE1, and ACE1) described in detail below originate from the latter region. After their generation near the coast, the anticyclonic eddies tend to propagate north-westward, whereas cyclonic vortices migrate south-westward (e.g. Chaigneau et al., 2008) into the open ocean. The seasonal cycle of eddy generation, based on all new eddy detections closer than $600 \mathrm{~km}$ off the coast, peaks in March and has its minimum in September (Fig. 2c), whereas cyclonic eddies exhibit a stronger amplitude. However, both anticyclonic as well as cyclonic eddies have their seasonal peak of formation in austral summer/autumn (February/March) and the lowest number at the end of austral spring (September; Fig. 2d).

The full eddy generation mechanisms are complex, whereby boundary current separation due to a sharp topographic bend is one important aspect of the eddy formation (Molemaker et al., 2015; Thomsen et al., 2016). It is suggested that anticyclones are generated due to instabilities of the Peru Chile Undercurrent (PCUC), whereas cyclonic eddies are formed from instabilities of the equatorward surface currents (Chaigneau et al., 2013). In this context the strength of the PCUC is essential (Thomsen et al., 2016). Observations as well as models show a weak seasonal variability in the PCUC off Peru which is stronger in austral summer and autumn (Thomsen et al., 2016; Chaigneau et al., 2013; Penven et al., 2005) and might explain the higher number of eddy generation during this season. Other model simulations have revealed a seasonal cycle in eddy flux that peaks in austral winter at the northern boundary of the OMZ, while it peaks a season later at the southern boundary (Vergara et al., 2016). The PCUC also experiences relatively strong fluctuations with periods of a few days to a few weeks (Huyer et al., 1991).

\subsection{Eddy observations from March 2014 to April 2015 at the Stratus mooring}

From March 2014 to April 2015 the Stratus mooring was located at $19^{\circ} 37^{\prime} \mathrm{S}, 84^{\circ} 57^{\prime} \mathrm{W}$, about $1500 \mathrm{~km}$ offshore in the oligotrophic open ocean. Oxygen, salinity, and meridional velocity component time series for the upper $600 \mathrm{~m}$ (Fig. 3; Supplement Fig. S2) record the passage of several eddies between March 2014 and April 2015. These observations are in agreement with the satellite data (SLA, SST, and Chl) at the mooring location and the 450 to $295 \mathrm{~m}$ geopotential anomaly (Fig. 3a).

At the time of the mooring deployment on 8 March 2014 an anticyclonic MWE with a radius of $43 \mathrm{~km}$ passed westward with the eddy centre to the north of the mooring while a 


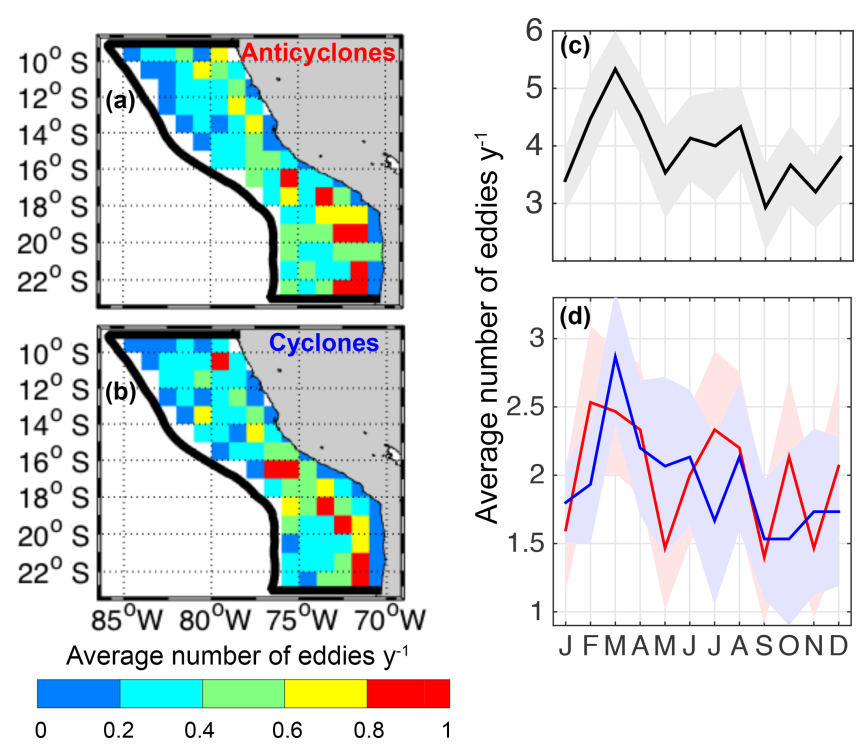

Figure 2. Number of (a) anticyclones and (b) cyclones generated in $1^{\circ} \times 1^{\circ}$ boxes (colours) between 1993 and 2015 closer than $600 \mathrm{~km}$ off the coast (coastal region). Seasonal cycle of the number of all eddies (black line), anticyclones (red line), and cyclones (blue line) generated in the coastal region are shown in (c) and (d).

cyclonic eddy was located south of the mooring site (Fig. 3b; Supplement movie M1). The mooring instruments recorded the parameter distribution at the southern rim of the MWE revealing anomalous low oxygen of less than $10 \mu \mathrm{mol} \mathrm{kg}-1$ and anomalous high salinity (temperature) of more than $34.65 \mathrm{psu}\left(10.6^{\circ} \mathrm{C}\right)$ in the eddy core in $300 \mathrm{~m}$ depth. It was accompanied with an upward bending of isopycnals above ( $\sim 250 \mathrm{~m}$ depth) and downward bending beneath $(\sim 350 \mathrm{~m}$ depth) the eddy core (Fig. 3c, d), which is typical for a modewater eddy in contrast to anticyclonic and cyclonic eddies. In late March 2014 the MWE had passed the mooring.

A strong oxygen decrease as well as a salinity increase with a strong downward displacement of the isopycnals at mid-depth in early August 2014 was related to an anticyclonic eddy (eddy ACE1; Fig. 3c) that passed the mooring south of it (Fig. 3b). In the upper $250 \mathrm{~m}$ the oxygen concentration increased with the maximum about 10 days later than the oxygen minimum at 290 to $600 \mathrm{~m}$ depth (Supplement Fig. S2). At $183 \mathrm{~m}$ depth, maxima in oxygen, temperature and salinity of $265 \mu \mathrm{mol} \mathrm{kg}-1,17.73^{\circ} \mathrm{C}$, and $35.38 \mathrm{psu}$, respectively, were reached in mid-August 2014 reflecting the deepening of the pycnocline which brings warmer, more saline and oxygen-rich waters to deeper levels. The ACE1 shows meridional velocities of more than $5 \mathrm{~cm} \mathrm{~s}^{-1}$ in the upper $300 \mathrm{~m}$ depth (Fig. 3e).

Another strong oxygen decrease influenced the oxygen distribution from early November 2014 to early January 2015. This anticyclonic eddy (eddy ACE2) had a radius of $53 \mathrm{~km}$ and showed the strongest downward displacement of the isopycnals in the 300 to $600 \mathrm{~m}$ range. At $350 \mathrm{~m}$ depth lowest oxygen values of $3.8 \mu \mathrm{mol} \mathrm{kg}-1$ were reached in early December 2014 (Fig. 3c). The massive deepening of the pycnoclines is also reflected by maxima in salinity ( $34.69 \mathrm{psu}$ ) and temperature $\left(10.33^{\circ} \mathrm{C}\right.$ ) in $350 \mathrm{~m}$ depth (not shown). The ACE2 shows high meridional velocities of more than $5 \mathrm{~cm} \mathrm{~s}^{-1}$ in the upper $450 \mathrm{~m}$ depth.

The lowest SLA and geopotential anomaly of the mooring deployment period was connected to a strong upward displacement of the isopycnals in February/March 2015 (Fig. 3c). The doming of the pycnoclines from January to March 2015 is associated with the typical signature of cyclonic eddies, which uplift colder, less saline and low-oxygen waters to shallower depths. Low values for oxygen, temperature, and salinity at $183 \mathrm{~m}$ depth of $69.1 \mu \mathrm{mol} \mathrm{kg}{ }^{-1}, 11.7^{\circ} \mathrm{C}$ and 34.54 psu in early February 2015 were related to a cyclonic eddy (CE) with a radius of $71 \mathrm{~km}$. Water properties of the CE may be associated with the Eastern South Pacific Intermediate Water which is transported by equatorward surface currents (Chaigneau et al., 2011).

According to the SLA satellite maps the centre of the MWE passed north of the mooring (Fig. 3b). The centre of the westward propagating ACE1 and the ACE2 passed the Stratus mooring only $14 \mathrm{~km}$ and $17 \mathrm{~km}$, respectively, south of it, hence the Stratus measurements were close to the centre of these two eddies (Fig. 3b; Supplement movie M1). However, satellite data show that the mooring captured only the northern segment of the ACE1 (Fig. 3b), therefore the radius of $28 \mathrm{~km}$ determined from measurements at the Stratus mooring is small in comparison to a mean radius of $40 \mathrm{~km}$ from satellite maps (Fig. 5a). Oxygen anomalies from January to March 2015 are related by two consecutive cyclonic eddies explaining the long-lasting and strong anomaly. The first eddy (CE) passed the mooring $43 \mathrm{~km}$ north of it and then merged with a second cyclonic eddy and passed to the south of the mooring (Fig. 3b).

Therefore, eddy events lead to a strong signal in water mass properties up to $196(40) \mu \mathrm{mol} \mathrm{kg}{ }^{-1}$ in oxygen, 0.84 (0.18) psu in salinity, and $6.0(1.9)^{\circ} \mathrm{C}$ in temperature in $183 \mathrm{~m}(350 \mathrm{~m})$ depth. The oxygen time series at $107 \mathrm{~m}$ depth (Supplement Fig. S2) does not show larger anomalies from the mean values in March and late August, at the time the Stratus mooring near sea surface temperature signal showed the maximum and minimum of a seasonal signal (Colbo and Weller, 2007; their Fig. 3). Hence, the maxima and minima described above for the Stratus time series at 183 and $350 \mathrm{~m}$ are clearly related to eddies and not related to the seasonal signal in the upper layer of the open ocean.

\subsection{Net transport of heat, salt, and oxygen via eddies in the ETSP}

Horizontal eddy transport can be explained by two mechanisms: (1) by eddy stirring, which occurs at the periphery of the eddy (e.g. Gaube et al., 2015; Chelton et al., 2011) and (2) by eddy transport of water masses trapped in the eddy 

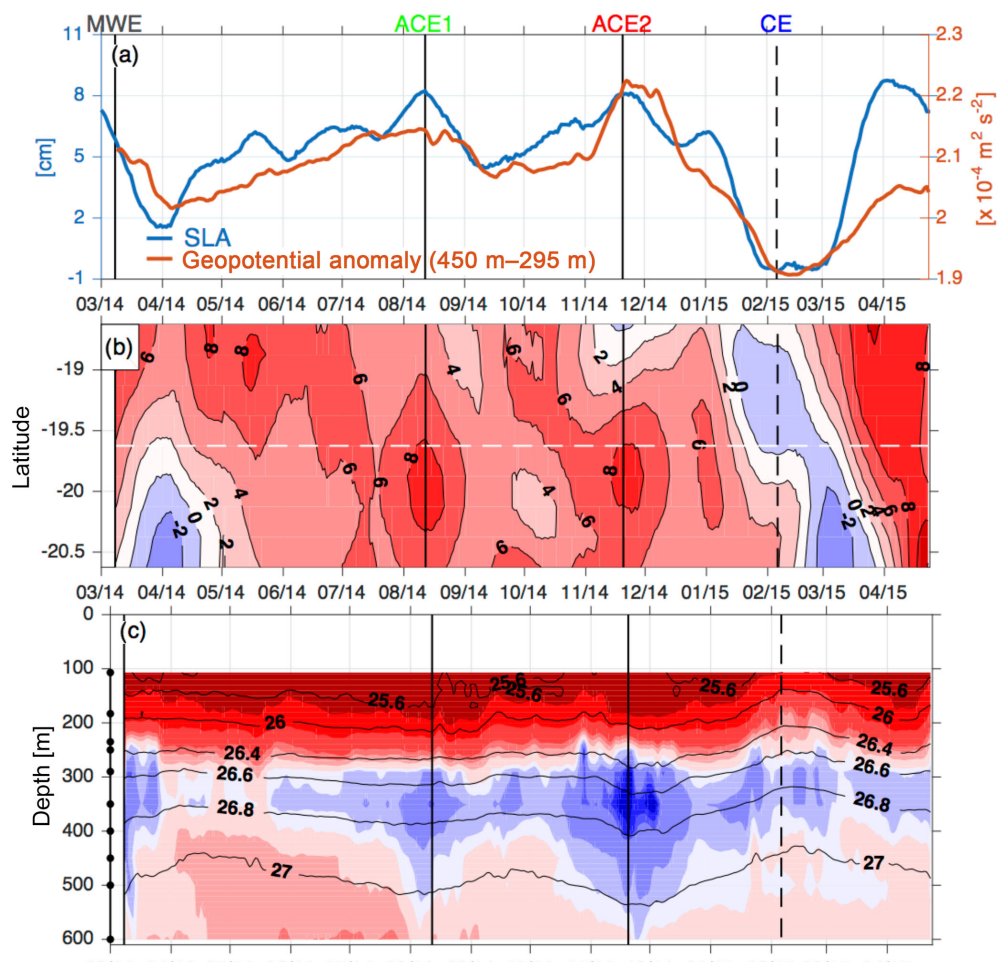

$\begin{array}{lllllllllllllllll}03 / 14 & 04 / 14 & 05 / 14 & 06 / 14 & 07 / 14 & 08 / 14 & 09 / 14 & 10 / 14 & 11 / 14 & 12 / 14 & 01 / 15 & 02 / 15 & 03 / 15 & 04 / 15\end{array}$
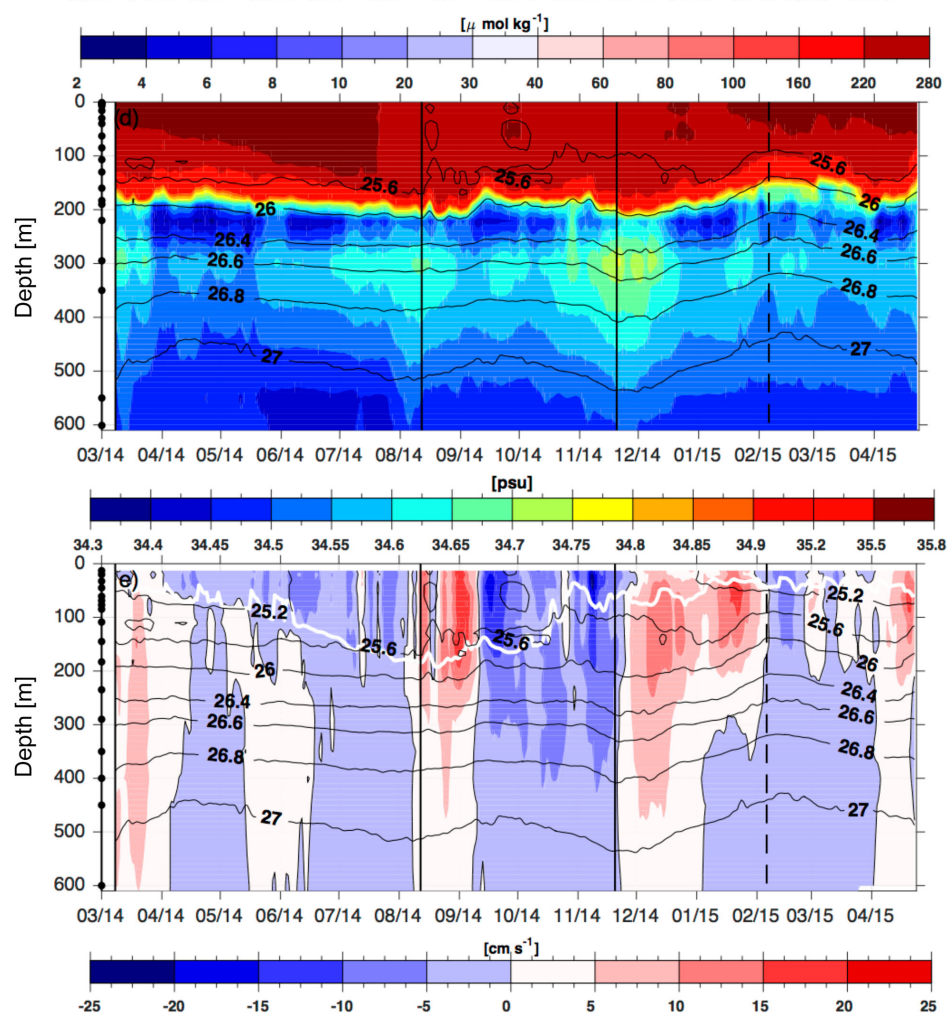

Figure 3. Time series for the deployment period 8 March 2014 to 25 April 2015 at the position of the Stratus mooring $\left(19^{\circ} 37^{\prime} \mathrm{S}, 84^{\circ} 57^{\prime}\right.$ W) for (a) weekly-delayed, high-pass filtered sea level anomaly (in cm; blue curve) and geopotential anomaly between 450 and $295 \mathrm{~m}$ depth in $\mathrm{m}^{2} \mathrm{~s}^{-2}$ (orange curve), (c) oxygen in $\mu \mathrm{mol} \mathrm{kg}-1$, (d) salinity, and (e) the meridional velocity component in $\mathrm{cm} \mathrm{s}^{-1}$, Hovmöller diagram (time-latitude) at the longitude position of the Stratus mooring for (b) SLA in cm. The white curve in (e) is the mixed layer depth defined for the depth where the potential density anomaly is $0.125 \mathrm{~kg} \mathrm{~m}^{-3}$ larger than at the surface. The black dots on the vertical line at the left mark the depths of the used oxygen (c), conductivity (d), and velocity (e) sensors and the black contour lines are selected density contours. Black solid (dashed) lines show the date of the passages of the anticyclonic (cyclonic) eddies. 

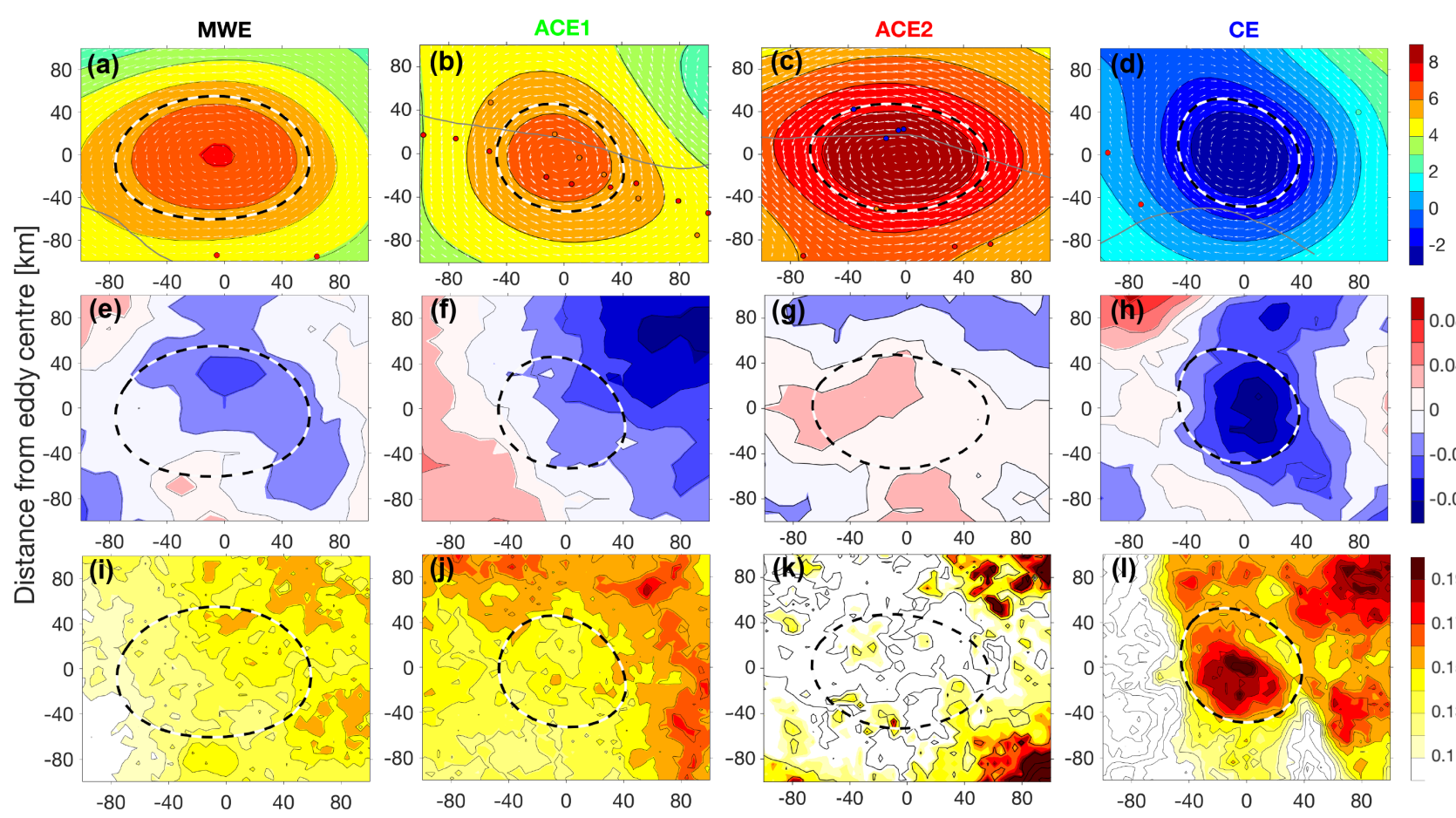

$\frac{\bar{\varepsilon}}{\frac{\overline{0}}{๘}}$
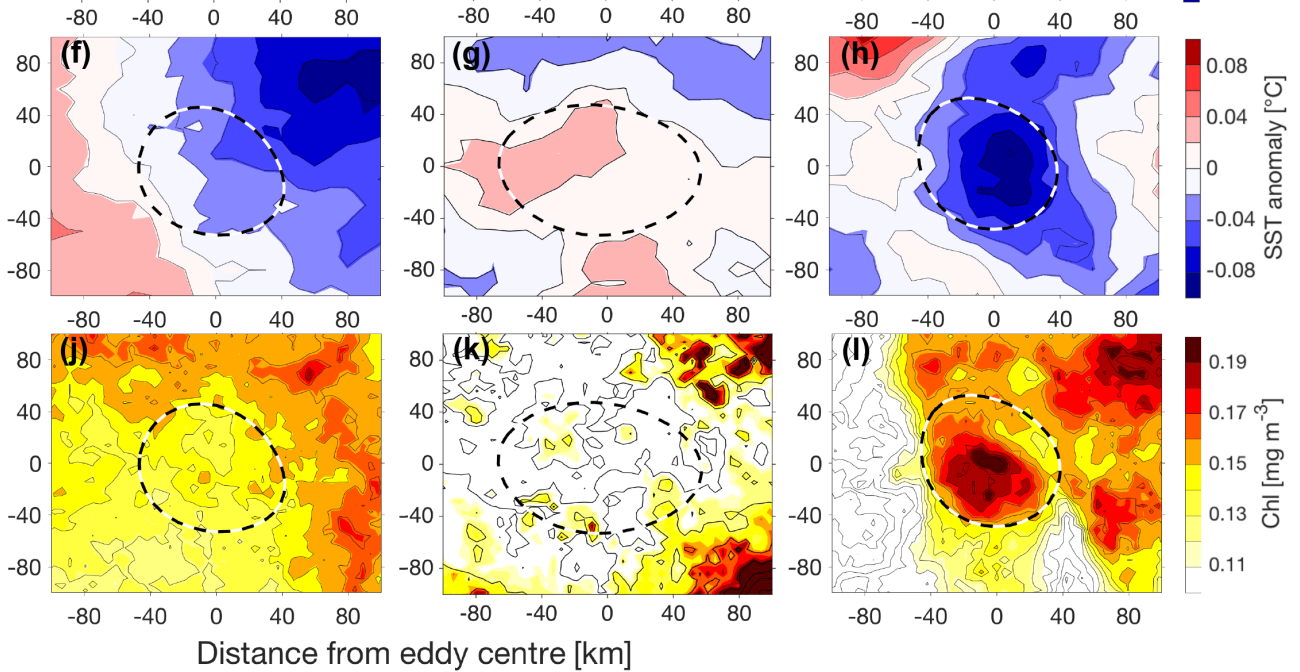

Figure 4. Composite of the MWE (a, e, i), ACE1 (b, f, j), ACE2 (c, g, k), and CE (d, h, l) surface signatures for SLA, SST anomaly, and Chl. The dashed black and white line is the eddy boundary, defined as the streamline of strongest velocity. The grey line in (a) and (d) is the position of the Stratus mooring during the eddy passage. The locations of the floats crossing the eddies are marked by coloured dots (float \#6900527 - red, \#6900529 - orange, \#6900530 - green, \#6900532 - blue).

interior (Gaube, 2013, 2015). We are focusing on the latter mechanism. The question of how much anomalous water properties an eddy is able to trap and transport into the open ocean depends on the relation between swirl velocity and propagation velocity. The MWE and the ACE2 have a similar propagation velocity of 4.3 and $4.2 \mathrm{~cm} \mathrm{~s}^{-1}$, respectively. The CE propagates fastest $\left(6 \mathrm{~cm} \mathrm{~s}^{-1}\right)$ and the ACE1 propagates slowest $\left(3.2 \mathrm{~cm} \mathrm{~s}^{-1}\right.$ ) (Fig. 6a), which fits well to the mean westward propagation speed of 3-6 and $4.3 \mathrm{~cm} \mathrm{~s}^{-1}$ estimated for eddies in the region off Peru (Chaigneau et al., 2008, 2011).

The observed swirl velocity at the Stratus mooring is in accordance with other values measured in the ETSP (Chaigneau et al., 2011; Stramma et al., 2013, 2014). All anticyclones (MWE, ACE1, and ACE2) show high rotation values in the upper $200 \mathrm{~m}$ depth with maximum velocities of 11,13 , and $17 \mathrm{~cm} \mathrm{~s}^{-1}$, respectively (Fig. 6a), which is between the values of mean anticyclonic eddies $\left(9 \mathrm{~cm} \mathrm{~s}^{-1}\right.$; Chaigneau et al., 2011) and a strong relatively young anticyclonic coastal mode-water eddy $\left(35 \mathrm{~cm} \mathrm{~s}^{-1}\right.$; Stramma et al., 2013). Further, the stronger swirl velocity of ACE2 agrees very well with an anticyclonic eddy, which passed the Stratus mooring during September to December 2011 at about the same season as for ACE2 $\left(19 \mathrm{~cm} \mathrm{~s}^{-1}\right.$; Stramma et al., 2014).
Typically for anticyclones, largest velocities occur in the upper $250 \mathrm{~m}$ depth, whereas the MWE shows weak rotation in the near surface and a deeper core instead. Below $250 \mathrm{~m}$ depth, the swirl velocity of ACE1 is significantly weaker than the swirl velocity of ACE2. Nonetheless, due to the much slower propagation velocity of ACE1 the fluid stays trapped within the eddy $(U / c>1)$ leading to a deep vertical extent of both anticyclones of $504 \mathrm{~m}$ (ACE1) and $523 \mathrm{~m}$ (ACE2) as described for mean anticyclones in the ETSP (Chaigneau et al., 2011).

Within the eddy boundaries of the two anticyclones (ACE1 and ACE2), positive anomalies of temperature and salinity were observed between 100 and $600 \mathrm{~m}$ depth (Fig. 6b, c). Between 150 and $200 \mathrm{~m}$ depth maximum anomalies of $2.1{ }^{\circ} \mathrm{C}$ (ACE1) and $1.5^{\circ} \mathrm{C}$ (ACE2) in temperature and $0.35 \mathrm{psu}$ (ACE1) and 0.24 psu (ACE2) in salinity were measured which are significantly higher than described for the mean of a composite of anticyclones $\left(0.8^{\circ} \mathrm{C}, 0.08 \mathrm{psu}\right.$; Chaigneau et al., 2011). Due to the uplift (depression) of isopycnals above (below) $200 \mathrm{~m}$ depth the MWE shows negative (positive) anomalies in temperature and salinity between 50 and $200 \mathrm{~m}$ (below $200 \mathrm{~m}$ ) depth, which are weak in comparison to the other two anticyclones. 


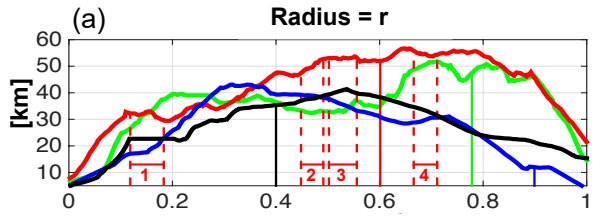

(b) Average maximal rotation $=\mathbf{u}$
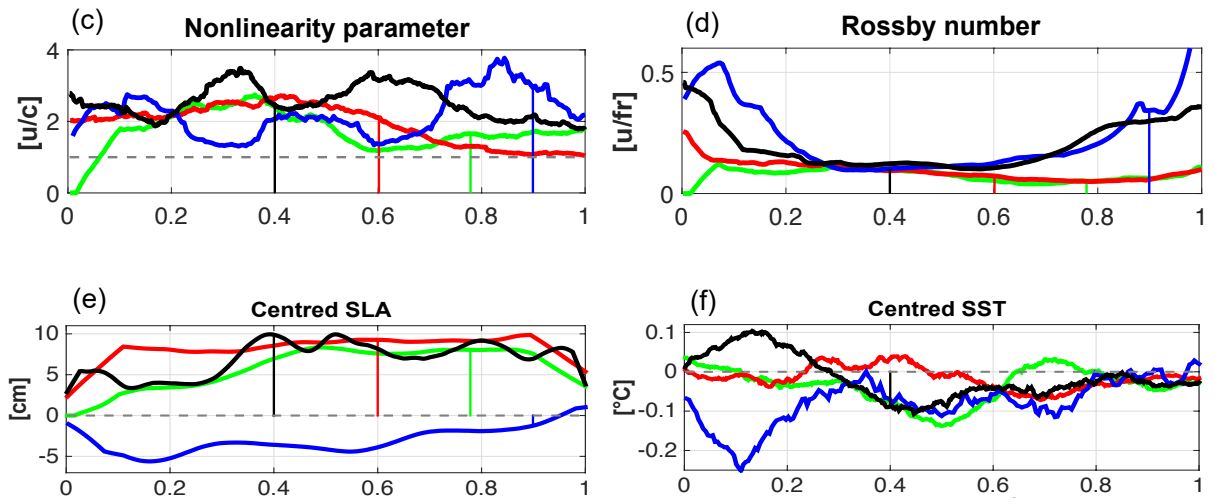

Normalized eddy lifetime

Figure 5. (a) Eddy radius, (b) averaged maximum rotation velocity, (c) nonlinearity parameter $(U / c)$, (d) Rossby number $(U / f r)$, (e) centred SLA, and (f) centred SST anomaly against normalized eddy lifetime of the ACE1 (green), ACE2 (red), CE (blue), and MWE (black). The coloured solid lines mark the passage at the Stratus mooring of the corresponding eddies. The residence times of the four floats trapped in the ACE2 are marked by red dashed lines in (a).
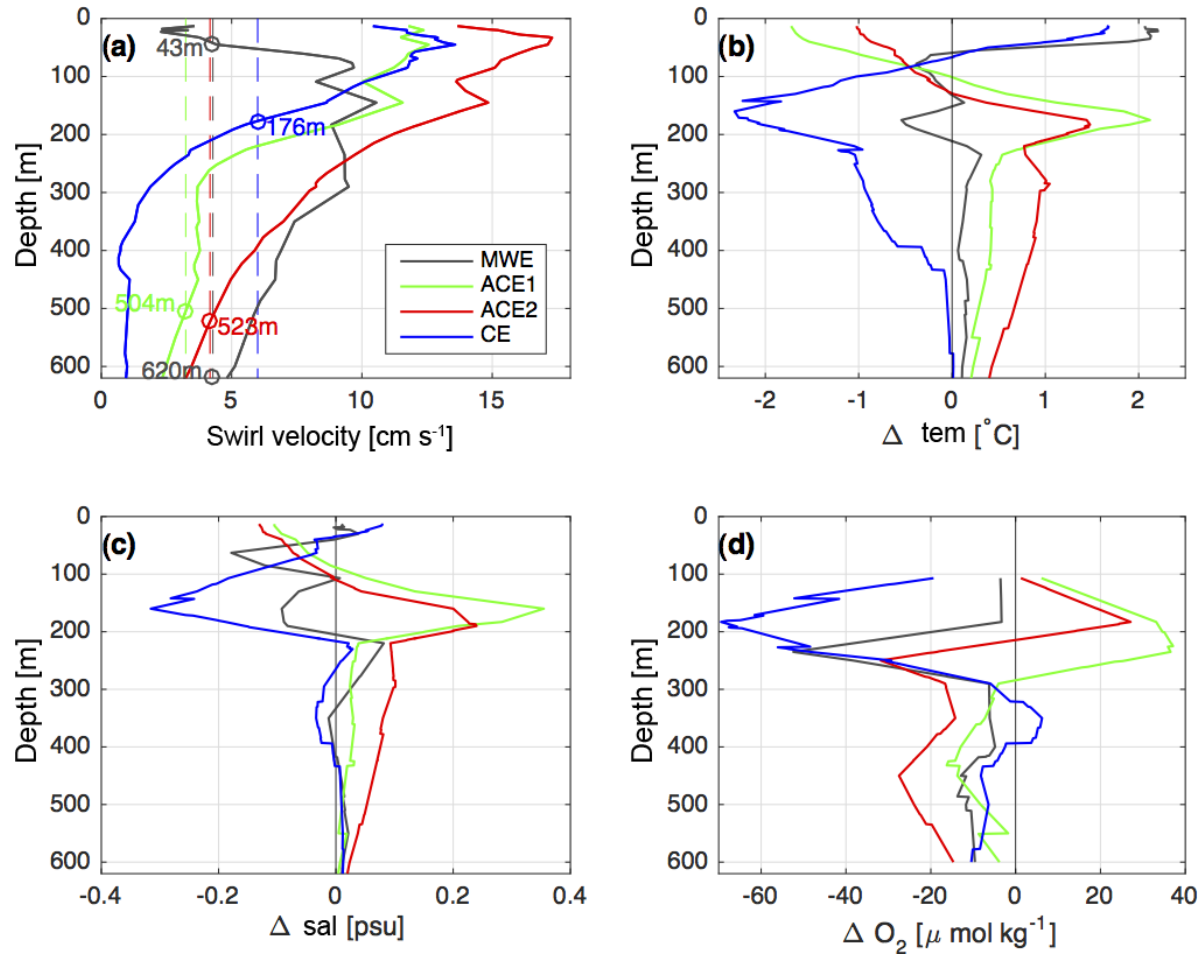

Figure 6. (a) Swirl velocity vs. depth (solid lines), propagation velocity (dashed lines), and vertical extent of the trapped fluid (circles) of three anticyclonic eddies (MWE: grey, ACE1: green, ACE2: red) and a cyclonic eddy (CE: blue). Profiles of anomalies of (b) temperature, (c) salinity, and (d) oxygen $\left(\mu \mathrm{mol} \mathrm{kg}{ }^{-1}\right.$ ) calculated as the difference between the core of MWE (grey), ACE1 (green), ACE2 (red), and CE (blue) as well as the 1-year mean of the Stratus mooring (10 April 2014-9 April 2015). 
Oxygen shows a mainly negative anomaly below 100, 220, and $280 \mathrm{~m}$ depth respectively within the anticyclones MWE, $\mathrm{AC} 1$, and AC2. Both the MWE and the ACE2 are having their largest negative anomalies in $250 \mathrm{~m}$ depth and a second minimum in $450 \mathrm{~m}$ depth, which is just above and below the core of the $\mathrm{OMZ}$ indicating the transport of low oxygenated water masses from a region with a larger vertical expansion of the OMZ (Fig. 6d). In the core depth of the OMZ at $350 \mathrm{~m}$ depth, only weak negative oxygen anomalies are possible as the oxygen content is already low, but still the passage of the stronger anticyclone ACE2 results in an oxygen decrease by $14 \mu \mathrm{mol} \mathrm{kg} \mathrm{kg}^{-1}$.

Water mass anomalies within the MWE lead to available heat, salt, and oxygen anomalies (AHA, ASA, AOA) of $1.0 \times 10^{18} \mathrm{~J},-3.1 \times 10^{10} \mathrm{~kg}$, and $-3.5 \times 10^{16} \mu \mathrm{mol}$. These values are about 5 times smaller in comparison to a modewater eddy that was also measured at the Stratus mooring in February/March 2012 (Stramma et al., 2014; Table 1). ASA is even negative in 2015 due to the strong doming in the upper $200 \mathrm{~m}$. As both mode-water eddies have about the same propagation speed and volume, the differences in water mass properties point towards seasonal or interannual variations of the water mass characteristics during their formation. The MWE is generated in February, when upwelling-favourable alongshore winds weaken and SST increases (Gutiérrez et al., 2011), whereas the mode-water eddy observed by Stramma et al. (2014) is generated in April, when the PCUC, which transports oxygen-deficient ESSW (Hormazabal et al., 2013), has its poleward maximum (Shaffer et al., 1999; Penven et al., 2005; Chaigneau et al., 2013). In addition, the MWE passed to the north of the Stratus mooring during its deployment, hence the method to define the fully MWE parameter might lead to higher deviations to the real eddy parameters.

The volume of ACE2 $\left(4.6 \times 10^{12} \mathrm{~m}^{3}\right)$ is in agreement with the mean anticyclones (Chaigneau et al., 2011) and the openocean anticyclone (Stramma et al., 2013) but 3 times larger than the weaker ACE1, which is partly due to the underestimated radius (Table 1). The AHA, ASA, and AOA of ACE2 are $8.1 \times 10^{18} \mathrm{~J}, 25.2 \times 10^{10} \mathrm{~kg}$, and $-3.6 \times 10^{16} \mu \mathrm{mol}$ and therefore far greater than the AHA, ASA, and AOA of ACE1 $\left(1.8 \times 10^{18} \mathrm{~J}, 5.5 \times 10^{10} \mathrm{~kg},-0.02 \times 10^{16} \mu \mathrm{mol}\right)$. The weak negative AOA of ACE1 result from the strong and positive oxygen anomaly in the upper $280 \mathrm{~m}$ depth in comparison to the background water mass. Strong differences between the results for ACE1 and ACE2 are of course due to the higher volume of the ACE2 but might also reflect the conditions at different seasons during the formation of the eddies leading to varying water mass properties. ACE1 (ACE2) is generated in austral summer (winter) when upwelling-favourable winds weaken (strengthen). Estimations of AHA and ASA within ACE2 match the mean values of Chaigneau et al. (2011). In comparison to the open-ocean eddy (Stramma et al., 2013) the AHA of the ACE2 is twice as high, but the AOA is only half as much (Table 1).
The cyclonic eddy in March 2015 (CE) has maximum velocities of $14 \mathrm{~cm} \mathrm{~s}^{-1}$ in $50 \mathrm{~m}$ depth (Fig. 6a). Due to the high translation speed of the $\mathrm{CE}$, the vertical extent of $176 \mathrm{~m}$ depth is much shallower than the vertical extent of the anticyclones, which is consistent with the mean cyclones (Chaigneau et al., 2011). The mean temperature shows a pronounced negative anomaly within the eddy boundaries between 70 and $430 \mathrm{~m}$ depth with a maximum anomaly of $-2.3{ }^{\circ} \mathrm{C}$ in $160 \mathrm{~m}$ (Fig. 6b) resulting in a negative AHA of $-8.9 \times 10^{18} \mathrm{~J}$. The salinity is negative between 40 and $220 \mathrm{~m}$ depth with a maximum anomaly of -0.32 psu in $160 \mathrm{~m}$ depth (Fig. 6c). This results in an extremely large negative ASA of $-41.5 \times 10^{10} \mathrm{~kg}$. Oxygen shows a strong negative anomaly in the upper $320 \mathrm{~m}$ having a maximum anomaly of $-69 \mu \mathrm{mol} \mathrm{kg}-1$ in $180 \mathrm{~m}$ depth (Fig. 6d) due to the uplift of the main thermocline leading to a negative AOA of $-6.5 \times 10^{16} \mu \mathrm{mol}$ for the 107 to $176 \mathrm{~m}$ depth layer. Although the volume of the CE is in good agreement with the mean values of Chaigneau et al. (2011), the estimated AHA and ASA are much higher (Table 1), which is likely due to strong seasonal variations during the generation of the CE. The CE is formed in austral winter off Peru when coastal alongshore winds intensify leading to an enhanced upwelling of cold and nutrient-rich and oxygenpoor water due to high biological production. Additionally, equatorward surface currents, which transport the relatively cold and fresh Eastern South Pacific Intermediate Water, are strongest during austral winter (Gunther, 1936).

Fluxes of mass, heat, salinity, and oxygen are estimated from the volume, AHA, ASA, and AOA (Table 1) for the period in which the MWE, ACE2, and CE cross the $85^{\circ} \mathrm{W}$ longitude at the Stratus mooring. The ratio of the heat fluxes of the three different eddies mirror the differences between volume, AHA, ASA, and AOA of the respective eddies because of the similar duration of the passages of the eddies. Transports of mass anomaly for the CE, ACE2, and MWE are again similar and range between $1.1 \mathrm{~Sv}$ for the $\mathrm{CE}$ and $1.8 \mathrm{~Sv}$ for ACE2 (Table 2). Due to the local conditions and different water masses during its formation, the CE shows a strong negative transport of heat $\left(-3.8 \times 10^{12} \mathrm{~W}\right)$ and salt $\left(-17.5 \times 10^{4} \mathrm{~kg} \mathrm{~s}^{-1}\right)$ across the mooring, whereas the ACE2 transports the highest positive amount of heat $\left(3.2 \times 10^{12} \mathrm{~W}\right)$ and salt $\left(10.0 \times 10^{4} \mathrm{~kg} \mathrm{~s}^{-1}\right)$ per year. Whereas the transport of heat and salt of the MWE is relatively small in comparison to the $\mathrm{CE}$ and $\mathrm{ACE} 2$, the transport of low oxygen water of $-1.8 \times 10^{10} \mu \mathrm{mol} \mathrm{s}^{-1}$ is in the same range as the $\mathrm{CE}$ and ACE2 due to a thick lens of low-oxygen water within the MWE.

Available anomalies of heat, salt, and oxygen of cyclonic and anticyclonic eddies gained from the Stratus mooring and from the literature (Table 1) are now used to estimate the relative contribution of long-lived eddies to fluxes of mass, heat, salt, and oxygen in an offshore area of the ETSP. The mean heat (in $\mathrm{W}$ ), salt (in $\mathrm{kg} \mathrm{s}^{-1}$ ), and oxygen transport ( $\mu \mathrm{mol} \mathrm{s}^{-1}$ ) are calculated by multiplying the amount of AHA, ASA, and AOA of the composite eddies with the number of eddies dis- 
Table 1. Properties and available heat, salt, and oxygen anomalies (AHA, ASA, AOA) with error bars of one mode-water eddy (MWE), two anticyclones (AE1 and AE2), and one cyclonic eddy (CE) measured at the Stratus mooring in 2014/2015 within the vertical layer of the coherent structure in comparison to measurements in February/March 2012 (Stramma et al., 2014; STR14, mode-water eddy) at the Stratus mooring, at $16^{\circ} 45^{\prime} \mathrm{S}, 83^{\circ} 50^{\prime} \mathrm{W}$ in November 2012 (Stramma et al., 2013; STR13, anticyclone) and mean values for 10-20 $\mathrm{S}$ relative to a mean climatology (Chaigneau et al., 2011; CH11, anticyclones and cyclones). Based on instruments available, the vertical extent for heat and salt computations (TS) and oxygen (OX) differs. It is important to note that the radius of the ACE1 might be underestimated.

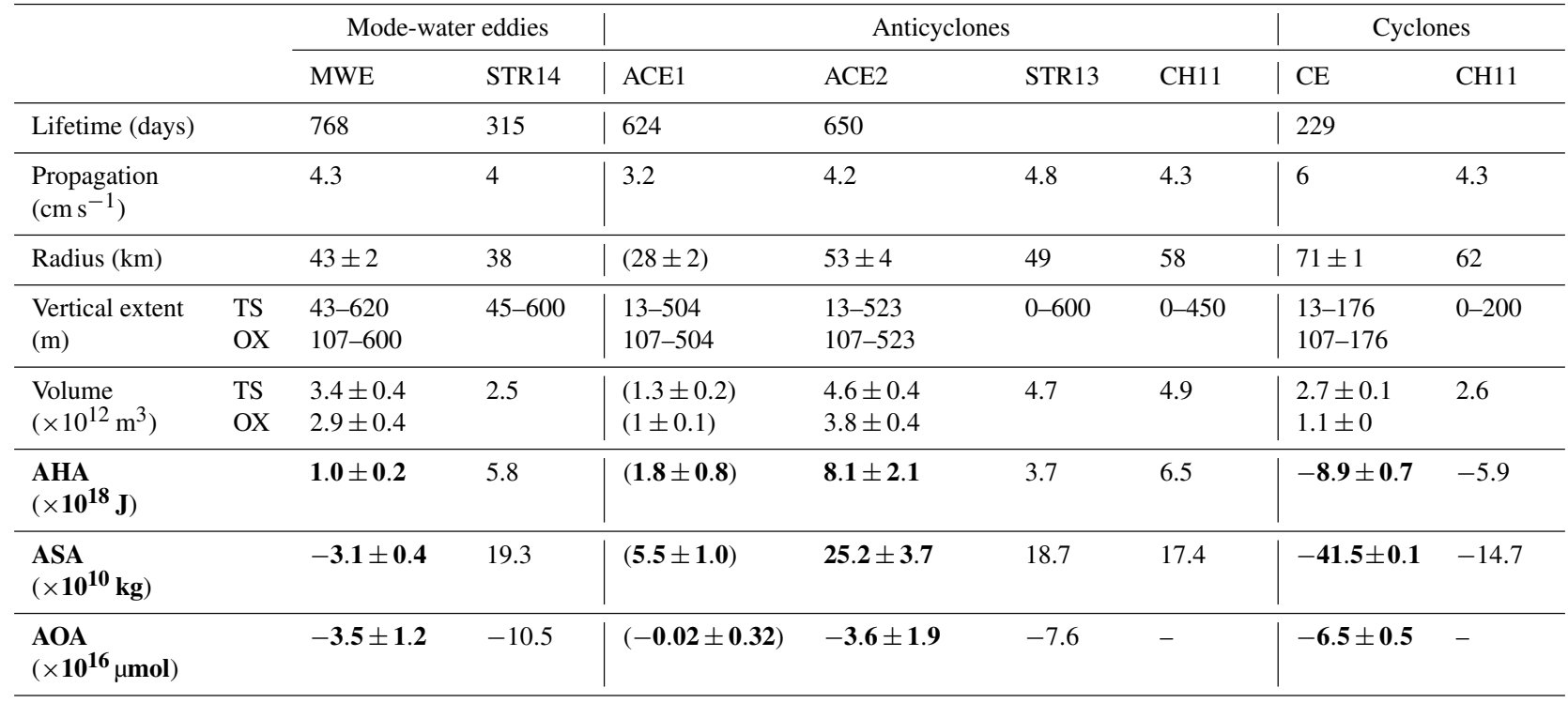

sipating per year in an offshore area (corresponding to a flux divergence). We define an area over a north-south direction from 10 to $24^{\circ} \mathrm{S}$. The transition area is bordered in the east by a line running parallel to the Peruvian and Chilean coast at a distance of $6^{\circ}$ and in the west by the $90^{\circ} \mathrm{W}$ longitude corresponding to a size of $\sim 1.7 \times 10^{6} \mathrm{~km}^{2}$. Based on averaged satellite measurements, 58.6 eddies of all eddies that are generated off the coast (Fig. 2) reach the offshore area per year from which 28.9 are cyclones and 29.7 are anticyclones. Also, 2.1 cyclones and 0.7 anticyclones and modewater eddies propagate into the area west of the $90^{\circ} \mathrm{W}$ longitude meaning that 26.8 of the cyclones and 29 of the anticyclones and mode-water eddies have dissipated and therefore transported a certain amount of heat, salt, and oxygen into the offshore zone. Based on the mean of AHA, ASA, and AOA for the composite eddies, the mean transport of heat (salt, oxygen) per year from the coastal region into the transition zone is $-6.4 \times 10^{12} \mathrm{~W}\left(-2.4 \times 10^{5} \mathrm{~kg} \mathrm{~s}^{-1},-5.7 \times\right.$ $\left.10^{10} \mu \mathrm{mol} \mathrm{kg}^{-1} \mathrm{~s}^{-1}\right)$ for cyclones and $4.7 \times 10^{12} \mathrm{~W}(1.5 \times$ $10^{5} \mathrm{~kg} \mathrm{~s}^{-1},-5.9 \times 10^{10} \mu \mathrm{mol} \mathrm{kg} \mathrm{kg}^{-1}$ ) for anticyclones and mode-water eddies in agreement with estimates for transport anomalies of heat and salt in this region by Chaigneau et al. (2011).

Heat and especially salt fluxes across the Stratus mooring as well as for the ETSP reveal an imbalance between anticyclones and cyclones which are due to a higher transport of anomalous cold and fresh water within cyclones from the coast off Peru and Chile into the upper open ocean. Both
Table 2. Mass, heat, salt, and oxygen transport with error bars of MWE, ACE2, CE across $85^{\circ} \mathrm{W}$ of the Stratus mooring 2014/2015.

\begin{tabular}{lrrr}
\hline & MWE & ACE2 & CE \\
\hline $\begin{array}{l}\text { Mass transport } \\
\text { (Sv) }\end{array}$ & $1.7 \pm 0.1$ & $1.8 \pm 0$ & $1.1 \pm 0$ \\
\hline $\begin{array}{l}\text { Heat transport } \\
\left(\times 10^{12} \mathrm{~W}\right)\end{array}$ & $0.5 \pm 0.1$ & $3.2 \pm 0.6$ & $-3.8 \pm 0.3$ \\
\hline $\begin{array}{l}\text { Salt transport } \\
\left(\times 10^{4} \mathrm{~kg} \mathrm{~s}^{-1}\right)\end{array}$ & $-1.6 \pm 0.3$ & $10.0 \pm 0.8$ & $-17.5 \pm 0.3$ \\
\hline $\begin{array}{l}\text { Oxygen transport } \\
\left(\times 10^{10} \mu \mathrm{mol} \mathrm{s}^{-1}\right)\end{array}$ & $-1.8 \pm 0.4$ & $-1.4 \pm 0.7$ & $-2.7 \pm 0.1$ \\
\hline
\end{tabular}

types of eddies show negative oxygen fluxes in the layer defined as the depth of the coherent structure of the eddy (Table 1) meaning that anticyclones and cyclones transport less oxygenated water into the upper and mid-depth open ocean and therefore have an impact on the balance and size of the OMZ in the ETSP, which is also confirmed by models (Frenger et al., 2018).

\subsection{Properties of the observed eddies MWE, ACE1/2, and $\mathrm{CE}$ during their lifetime}

With the help of satellite data the four eddies (MWE, ACE1/2, and CE) could be identified and followed from ar- 
eas near the Peruvian and off the Chilean coast to the areas of dissipation westwards of the Stratus mooring in the open ocean. The trajectories of the three anticyclonic eddies (MWE, ACE1/2) were extrapolated to the formation regions near the coast between 20 and $23^{\circ} \mathrm{S}$ (Fig. 1). The CE formed during end of July 2014 off the Peruvian coast during the winter season when upwelling is usually strong and decayed in mid-March 2015 after propagating $1200 \mathrm{~km}$ in more than 7 months. Both the MWE and the ACE1 started off the Chilean coast during the end of the summer season with usually low upwelling. The MWE can be followed for about 2 years till March 2015 propagating $2880 \mathrm{~km}$. The ACE1 is tracked for 620 days until it decayed at the end of November 2014, after propagating $1750 \mathrm{~km}$. The ACE2, which was generated during the upwelling season at the end of winter in September 2013 and decayed in June 2015, propagated westward for $2350 \mathrm{~km}$ in 650 days.

As expected from the polarity depending meridional deflection of all eddies (anticyclones - equatorward, cyclones poleward), the individual pathways of the ACE1 and ACE2 also show a north-westward direction whereas the $\mathrm{CE}$ migrates more south-westwards (Fig. 1a). Note that the MWE shows no clear meridional deflection on the way to the west.

Anticyclonic eddies (MWE, ACE1/2) are associated with a positive SLA, wherein ACE2 shows the strongest mean elevation of all anticyclonic eddies of $8 \mathrm{~cm}$ (Fig. 4c) and cyclonic eddies are identified by a negative SLA, wherein the CE shows a mean minimum SLA of $-2 \mathrm{~cm}$ in the centre of the eddy (Fig. 4d). Nevertheless, the CE showed the largest SLA differences at the Stratus mooring (Fig. 3a). In general, mode-water eddies are difficult to detect by satellite altimetry due to a relatively weak velocity near the surface (Fig. 6a), which is generated by the typical distribution of the isopycnals. Therefore, it is noteworthy that the MWE has a stronger SLA $(7 \mathrm{~cm})$ than the relatively weak ACE1 $(6 \mathrm{~cm})$. The SLA of the MWE indicates higher variability during its lifespan than the other eddies (Fig. 5e). The maximum SLA of the anticyclones is obtained during their mid-age, whereas the SLA of the CE decreases after the very beginning.

Due to the uplift of the seasonal pycnocline in both eddies, MWE and CE, cold and nutrient rich water is upwelled into the euphotic zone leading to enhanced biological production, which is reflected by negative SST anomalies of $-0.04{ }^{\circ} \mathrm{C}$ (MWE, Fig. 4e), $-0.08^{\circ} \mathrm{C}$ (CE, Fig. 4h), and a high chlorophyll concentration of $0.19 \mathrm{mg} \mathrm{m}^{-3}$ (CE, Fig. 4l). Surprisingly, the mean SST (Chl) of the ACE1 and ACE2 are negative (high) and around zero, respectively, as one would expect positive (low) SST (Chl) anomalies due to the depression of the thermoclines. The development of the SST predominantly shows negative anomalies with short periods of positive anomalies for the anticyclones (Fig. 5f).

The development of further eddy properties (radius, $\mathrm{km}$; rotating velocity, $\mathrm{m} \mathrm{s}^{-1}$; nonlinearity parameter; and Rossby number) during the normalized lifespan are shown in Fig. 5 indicating that the observed eddies pass the Stratus mooring during their mid-age (MWE and ACE2) and during the end of their lifetime (ACE1 and CE). The anticyclones ACE1/2 have their maximum radius during the last third of their lifetime, whereas the development of the radius of the MWE is symmetric and the radius of the CE increases during the first third of its lifetime (Fig. 5a). Note the decreasing maximum rotation velocity of the ACE2 during the second half of its lifetime (Fig. 5b).

Water mass anomalies can only be preserved within an eddy if the feature is nonlinear and maintains its coherent structure. During their full lifetime, the nonlinear parameter $U / c>1$ for all eddies and confirms the coherent feature (Fig. 5c). Nonetheless, significant variations in the nonlinear parameter $U / c$ determined at the surface might indicate changes in the volume of the eddies, which can be influenced by friction, stratification, fluctuations of the mean flow, or the collapse with other eddies. Maps of SLA show a permanent change of the radius due to an irregular and varying shape and the merging with other eddies (Supplement: movie M1), which makes it sometimes difficult to track an eddy during its whole lifetime. Fluctuations are also produced by the coarse resolution of the satellite data $\left(0.25^{\circ} \times 0.25^{\circ}\right)$ and the merging algorithms used by AVISO. However, the MWE and CE show stronger fluctuations of the nonlinear parameter than the ACE1/2, which probably mirrors the higher variability in the swirl velocity of both eddy types (Fig. 5b). Nonetheless, the nonlinear parameter $U / c$ is always higher than 1 and therefore indicates a trapped volume despite strong fluctuations at the surface. The small variations in the eddy properties of the ACE2 (Fig. 5a-e) suggest a relatively stable structure.

All eddies indicate a Rossby number $R_{O}<1$ describing the typical scale for mesoscale eddies (Fig. 5d). The mean life cycle of an eddy consists of a growth and decaying phase, both lasting about $20 \%$ of its lifetime and a stable phase in between (Liu et al., 2012; Frenger et al., 2015; Samelson et al., 2014). This is consistent with our observations showing constant Rossby numbers of less than 0.1 between 0.2 and 0.8 reflecting a stable, geostrophic phase over $60 \%$ of the lifetime of all eddy types. At the beginning and at the end of the eddy lifetime the Rossby numbers are increasing and indicating the influence of possible ageostrophic processes. But the increase in the Rossby number for both anticyclones is not as striking as for the MWE and CE. However, a very detailed and exact discussion about the evolution of the Rossby radius (and also the radius, the average maximum rotation, and the nonlinearity) and possible ageostrophic processes is not possible due to the coarse resolution of the underlying SLA data.

\subsection{Observations of Argo floats within the eddy-core of ACE2 during its mid-age}

ACE2 has been tracked via SLA from March 2014 on, passed the Stratus mooring in November 2014 and decayed in June 

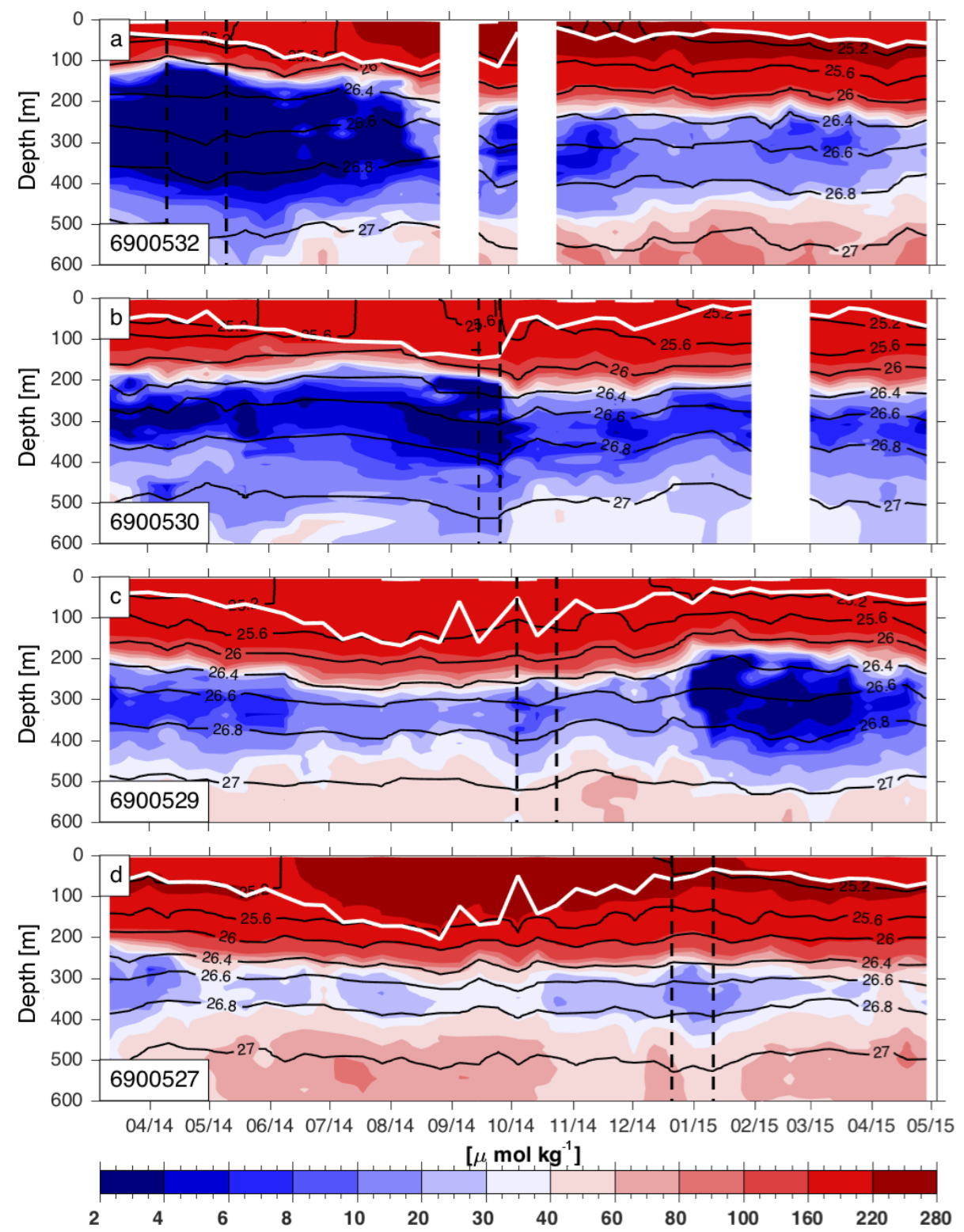

Figure 7. Distribution of oxygen (in $\mu \mathrm{mol} \mathrm{kg} \mathrm{kg}^{-1}$, coloured) and density (black lines) vs. time in the upper $600 \mathrm{~m}$ depth of floats 6900532 (a), 6900530 (b), 6900529 (c), and 6900527 (d) which have been trapped within the ACE2 at different stages. The residence time in ACE2 of the floats in April/May 2014, September 2014, October 2014, and December 2014/January 2015 is marked by dashed black lines. The white curve is the mixed layer depth defined for the depth where the potential density anomaly is $0.125 \mathrm{~kg} \mathrm{~m}^{-3}$ larger than at the surface.

2015. During this period, four floats (Fig. 7) were captured within the ACE2 during its westward propagation at different times providing information about different stages of the eddy. The first float (\#6900532) was trapped in the period from mid-April to mid-May 2014 at $19.9^{\circ} \mathrm{S}, 77.1^{\circ} \mathrm{W}$ (Supplement: movie M1). The eddy shows the core at about isopycnal $26.4 \mathrm{~kg} \mathrm{~m}^{-3}(\sim 180 \mathrm{~m} \mathrm{depth})$ with extremely low oxygen of less than $4 \mu \mathrm{mol} \mathrm{kg}{ }^{-1}$ between 150 and $400 \mathrm{~m}$ depth (Fig. 7a) and enhanced salinity of more than $34.8 \mathrm{psu}$ in the upper $240 \mathrm{~m}$ depth (Fig. 8a). The warm, salty, and oxygen-depleted water mass of the core of the ACE2 co- incides with the water mass of the likely formation region of the ACE2 obtained from the monthly isopycnal and mixed-layer ocean climatology (MIMOC; Schmidtko et al., 2013; Fig. 9a, b) reflecting the characteristics of the oxygendepleted ESSW. The ESSW is carried poleward by the secondary southern subsurface countercurrent (Montes et al., 2014), feeds the subsurface PCUC (Hormazabal et al., 2013), and is then transported along the Peruvian and Chilean coast where anticyclonic eddies are likely generated (Chaigneau et al., 2011). 

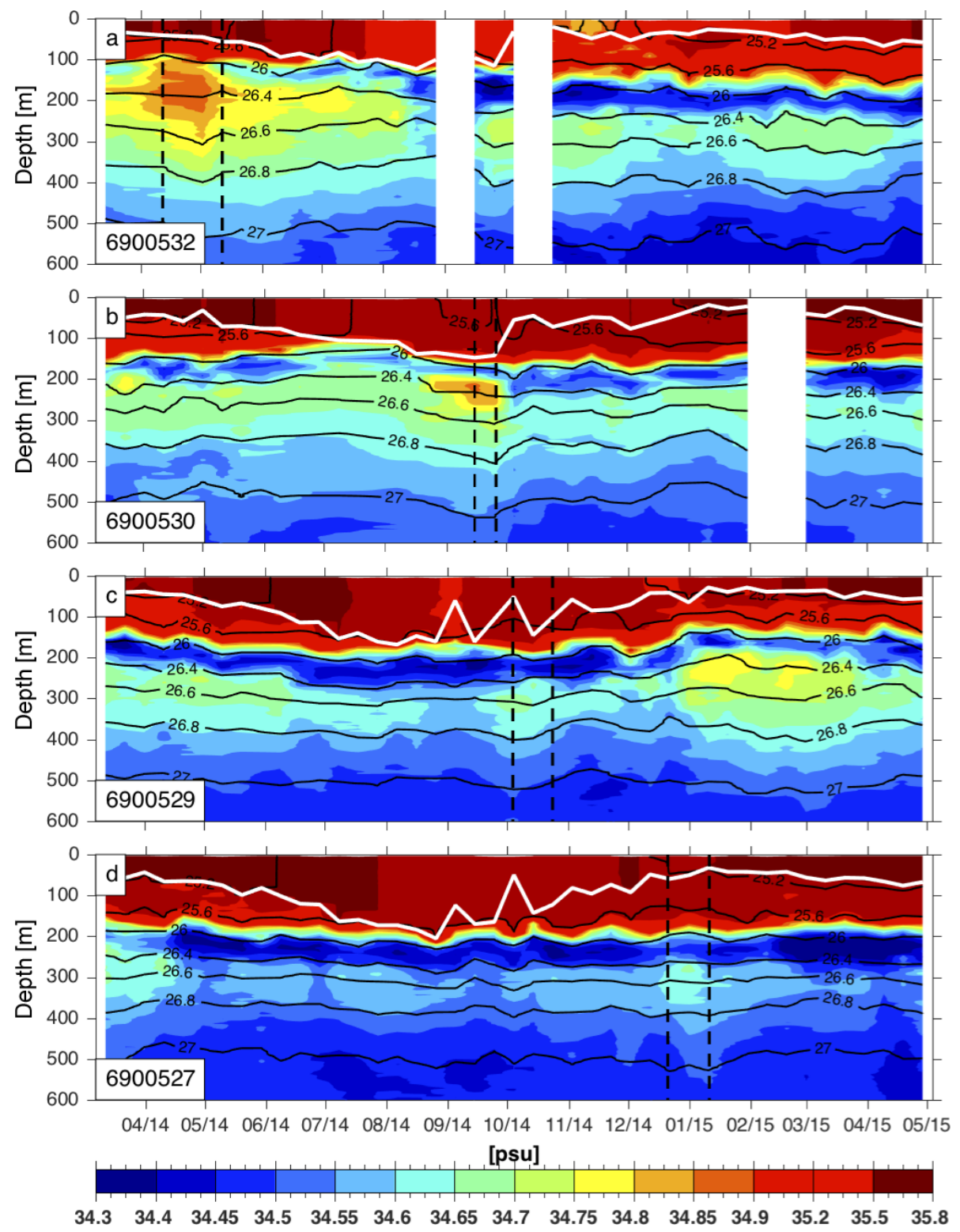

Figure 8. Same as Fig. 7 but for salinity distribution.

In September 2014, about 4 months later and more than $6^{\circ}$ further west at $19.4^{\circ} \mathrm{S}, 83.4^{\circ} \mathrm{W}$ a second float (\#6900530) was trapped in the same eddy ACE2 (Supplement: movie M1). The core was still located at isopycnal $26.4 \mathrm{~kg} \mathrm{~m}^{-3}$ ( $\sim 230 \mathrm{~m}$ depth) showing minimum oxygen values of less than $4 \mu \mathrm{mol} \mathrm{kg} \mathrm{kg}^{-1}$ (Fig. 7b) and maximum salinity of more than 34.8 psu (Fig. 8 b) between 200 and $280 \mathrm{~m}$ depth. However, the vertical extent of anomalously high salinity and anomalously low oxygen has decreased (Fig. 9a, b) which is likely due to lateral mixing. Mixing mostly takes place above the core of the eddy between the density layers $\sigma_{\theta}=25.7$ and $\sigma_{\theta}=26.3 \mathrm{~kg} \mathrm{~m}^{-3}$ (Supplement Fig. S3) with largest changes in oxygen $\left(0.5 \mu \mathrm{mol} \mathrm{kg}{ }^{-1} \mathrm{day}^{-1}\right)$, temperature $\left(-0.007^{\circ} \mathrm{C}\right.$ day $\left.^{-1}\right)$, and salinity $\left(-0.002\right.$ psu day $\left.^{-1}\right)$ at about $\sigma_{\theta}=26.0 \mathrm{~kg} \mathrm{~m}^{-3}$. This density level corresponds to a depth between 100 and $170 \mathrm{~m}$, where a high swirl velocity exists within the ACE2 (Fig. 6a), which is essential to keep up the coherent structure.

Shortly after, in October 2014, a third float (\#6900529) stayed in the ACE2 at about $20.4^{\circ} \mathrm{S}, 82.8^{\circ} \mathrm{W}$. The strongest water property anomaly is now located at isopycnal $26.6 \mathrm{~kg} \mathrm{~m}^{-3}$ ( $\left.\sim 310 \mathrm{~m} \mathrm{depth}\right)$ showing minimum oxygen of less than $8 \mu \mathrm{mol} \mathrm{kg}^{-1}$ (Fig. 7c). The salinity anomaly transported within the eddy has declined further to about 34.65 psu (Fig. 8c). The development of the water mass properties within the eddy points towards mixing along density surfaces between $\sigma_{\theta}=26.0 \mathrm{~kg} \mathrm{~m}^{-3}(\sim 190 \mathrm{~m})$ and $\sigma_{\theta}=26.5 \mathrm{~kg} \mathrm{~m}^{-3}(280 \mathrm{~m})$. The changes are strongest 

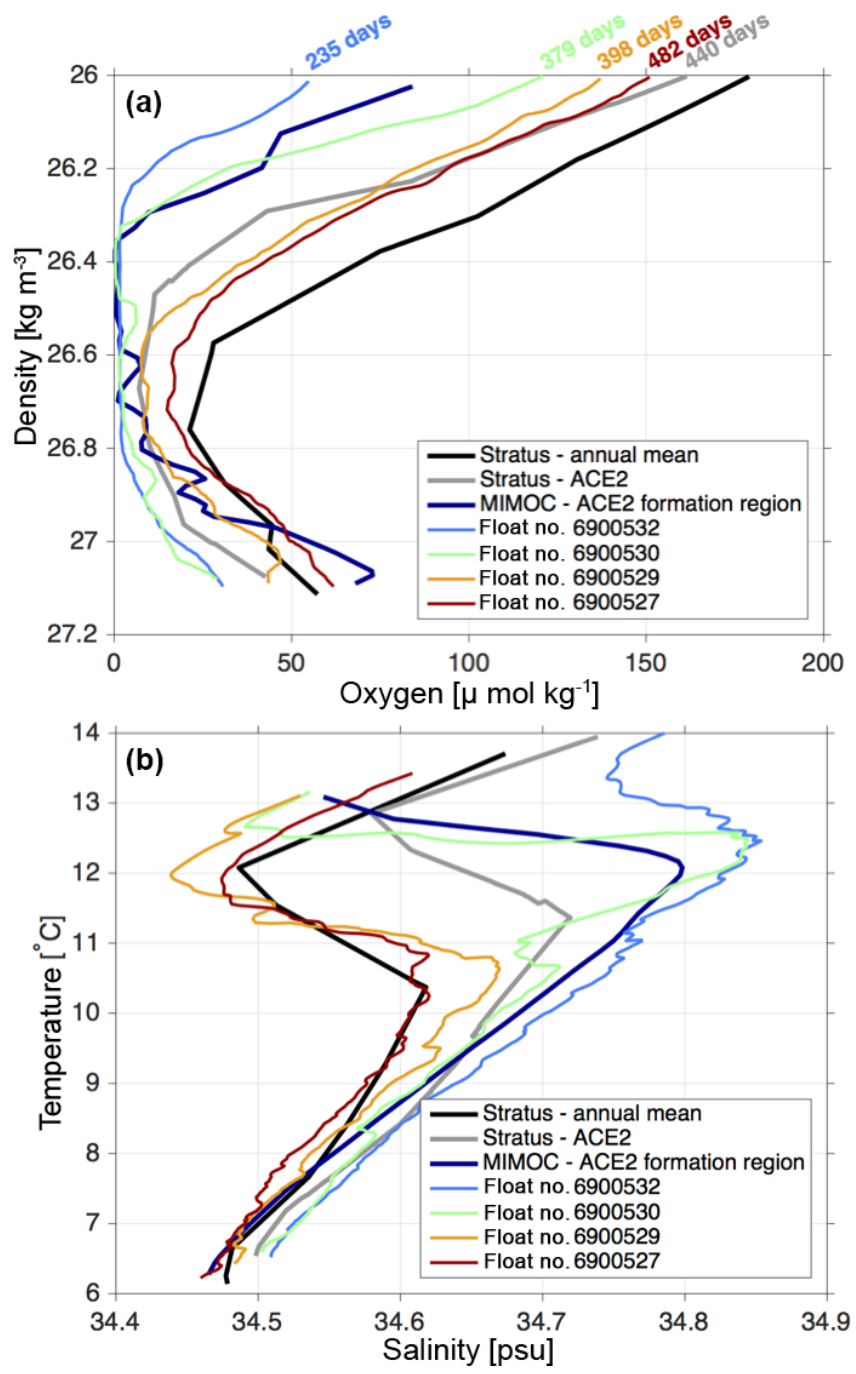

Figure 9. Profiles of (a) oxygen vs. density and (b) temperaturesalinity diagrams at the Stratus mooring $\left(19^{\circ} 37^{\prime} \mathrm{S}, 84^{\circ} 57^{\prime} \mathrm{W}\right)$ for a 1-year mean (10 April 2014 to 9 April 2015; black) and during the passage of the ACE2 in November 2014 (grey line), from the estimated formation region at $23^{\circ} \mathrm{S}, 71^{\circ} \mathrm{W}$ from the MIMOC climatology (dark blue) and from data of four floats (69005-27, -29, -30 , and -32) trapped in the ACE2 (for coloured lines see legend). The age of the ACE2 in days during the respective measurement is indicated in the upper panel. The age of the ACE2 (in days) at the time of the respective float measurements is marked in (a).

above the core of the eddy at about $\sigma_{\theta}=26.3 \mathrm{~kg} \mathrm{~m}^{-3}$ ( $\sim 205$ to $240 \mathrm{~m})$ showing the mixing of oxygen-rich $\left(2.8 \mu \mathrm{mol} \mathrm{kg}{ }^{-1} \mathrm{day}^{-1}\right)$, colder $\left(-0.07^{\circ} \mathrm{C} \mathrm{day}^{-1}\right)$ and fresher water $\left(-0.017 \mathrm{psuday}^{-1}\right.$ ) into the ACE2 (Supplement Fig. S3).

Decreased anomalies might also be related to the fact that the float did not capture the eddy centre as it was located in the south-east rim of the eddy (Fig. 4c). Whereas the salinity measurements of the float differ from those of the Stratus measurements obtained during the passage of the ACE2
(Fig. 9b), the oxygen anomaly transported in the core agrees well (Fig. 9a).

After the ACE2 has passed the Stratus mooring in November 2014, the last of the four floats (\#6900527) was trapped at the southern rim of the eddy (Fig. 4c) from December 2014 to January 2015 at about $20.4^{\circ} \mathrm{S}, 86.4^{\circ} \mathrm{W}$. The eddy core is still clearly visible, although water mass properties within the core of the ACE2 has further changed (oxygen $>10 \mu \mathrm{mol} \mathrm{kg}{ }^{-1}$, Fig. 7d) and the vertical extent of the eddy has declined. Mixing of slightly oxygen-richer water can be observed over the whole water column (Supplement Fig. S3a), whereas warmer and more saline water is entrained in the upper part of the eddy $\left(\sigma_{\theta}>26.3 \mathrm{~kg} \mathrm{~m}^{-3} \cong 240 \mathrm{~m}\right.$ depth) and colder and fresher water below. These changes might also be due to the location of the float outside the eddy boundary.

\section{Discussion and outlook}

The ETSP is known for its high eddy frequency (Chaigneau et al., 2008). There is still limited knowledge in this region about the dynamics of eddies especially on their effective transport and their dissipation. In this study the activity of three different types of eddies (mode water, anticyclonic, and cyclonic eddy) during their westward propagation was investigated from the formation area in the upwelling area off Peru and Chile into the open ocean. The focus was on the development of the eddies, seasonal conditions during their formation, their life cycles and fluxes, and the change of water mass properties transported within the isolated eddies using a broad range of observational data such as SLA, SST, and Chl from satellites as well as hydrographic data and oxygen from the Stratus mooring and from Argo floats.

Available heat, salt, and oxygen anomalies could be computed for the investigated eddies. Generally, heat and salt anomalies transported within eddies are positive for anticyclones and negative for cyclones and might be compensated for as they are of about the same amount (Chaigneau et al., 2011). In this study the negative and positive heat anomalies of the CE $\left(-8.9 \times 10^{18} \mathrm{~J}\right), \mathrm{ACE} 2\left(8.1 \times 10^{18} \mathrm{~J}\right)$, and MWE $\left(1.0 \times 10^{18} \mathrm{~J}\right)$ almost balance each other. In contrast, the sum of negative and positive salt anomalies transported within the CE $\left(-41.5 \times 10^{10} \mathrm{~kg}\right)$, ACE2 $\left(25.2 \times 10^{10} \mathrm{~kg}\right)$, and MWE $\left(-3.1 \times 10^{10} \mathrm{~kg}\right)$ is unbalanced. The AOA is negative for all types of eddies (MWE: $-3.5 \times 10^{16} \mu \mathrm{mol}$; ACE2: $-3.6 \times 10^{16} \mu \mathrm{mol}$; CE: $\left.-6.5 \times 10^{16} \mu \mathrm{mol}\right)$, whereby the transport of oxygen-poor water from the upwelling region into the open ocean is more surface intensified due to the shallow structure of the cyclonic eddies. A mode-water eddy observed by Stramma et al. (2014) was generated in year 2011, which is considered as a La Niña period, when generally lower oxygen and higher salinity values exist in the upper $100 \mathrm{~m}$ depth (Stramma et al., 2016) leading to higher anomalies of salt and oxygen of the mode-water eddy observed by 
Stramma et al. (2014) in comparison to the actual MWE. Therefore, seasonal variability such as fluctuation of alongshore upwelling-favourable winds off Peru and Chile as well as interannual variability such as El Niño or La Niña have an impact on the water mass properties trapped and transported within eddies from the coast of Peru and Chile into the open ocean reflecting the high variability of AHA and ASA.

For the Atlantic Ocean the low-oxygen eddy cores have been attributed to high productivity in the surface (Schütte et al., 2016b), enhanced respiration of sinking organic material at subsurface depth (Fiedler et al., 2016), and a strong isolation of the eddy core (Karstensen et al., 2017). An anticyclonic mode-water eddy observed in the Pacific at the Stratus mooring in February/March 2012 indicated high primary production just below the mixed layer (Stramma et al., 2014). According to a global investigation of Argo floats, the eastern South Pacific off Peru and Chile seems to have the highest amount of MWEs, which are also deep reaching compared to other regions (Zhang et al., 2017; their Fig. 2). Nevertheless, in the mooring deployment period 2014/2015 only one MWE crossed to the north of the mooring and the results have to be regarded with caution. Even though the AHA and ASA of the MWE are small in comparison to both the anticyclonic eddies and the cyclonic eddy the transport of low oxygen water is in the same range as the other eddies due to the typical thick lens of low oxygen water within mode-water eddies.

From a combination of satellite data and Argo profiles, long-lived eddies (lifetime longer than 30 days) in the Peru-Chile upwelling system (55\% of the sampled anticyclonic eddies) had subsurface-intensified maximum temperature and salinity anomalies below the seasonal pycnocline, whereas $88 \%$ of the cyclonic eddies are surface intensified (Pegliasco et al., 2015). The $55 \%$ subsurface-intensified anticyclonic eddies represent mode-water eddies while the $45 \%$ surface intensified anticyclones are "regular" anticyclonic eddies. Observations and model results for the California Current system showed a good agreement between observed and modelled eddy structures (Kurian et al., 2011).

Satellite-based estimate of the surface-layer eddy heat flux divergence, while large in coastal regions, is small when averaged over the south-east Pacific Ocean, suggesting that eddies do not substantially contribute to cooling the surface layer in this region (Holte et al., 2013). In this study, the release of fluxes of heat (cyclones: $-6.4 \times 10^{12} \mathrm{~W}$; anticyclones: $\left.4.7 \times 10^{12} \mathrm{~W}\right)$ and salt $\left(-2.4 \times 10^{5} \mathrm{~kg} \mathrm{~s}^{-1} ; 1.5 \times\right.$ $10^{5} \mathrm{~kg} \mathrm{~s}^{-1}$ ) estimated from long-lived eddies dissipating in the ETSP confirms the discrepancy between different types of eddies leading to a net transport of colder and fresher water from the formation regions off Peru and Chile into the open ocean. In contrast, all three types of eddies show a negative oxygen flux of $-5.7 \times 10^{11} \mu \mathrm{mol} \mathrm{kg} \mathrm{kg}^{-1} \mathrm{~s}^{-1}$ for cyclones and $-5.9 \times 10^{10} \mu \mathrm{mol} \mathrm{kg}{ }^{-1} \mathrm{~s}^{-1}$ for anticyclones and mode-water eddies pointing towards an active role of eddies in balancing and shaping the OMZ confirmed by model studies (Frenger et al., 2018).

Thus, the variability of eddy generation on different timescales might be an important factor for the variability in the OMZ. Eddy generation off the coast between 8 and $24^{\circ} \mathrm{S}$ peak in austral summer/spring, which agrees with the strengthening of the PCUC and the possible mechanism of the generation of eddies due to instabilities. However, this is not in agreement with model simulations showing an eddyinduced offshore transport off Peru that peaks in austral spring (winter) at the southern (northern) boundary of the OMZ (Vergara et al., 2016). As the PCUC also shows strong fluctuations lasting a few days up to a few weeks (Huyer et al., 1991) it might be difficult to determine a seasonal dimension between the PCUC and the rate of eddy formation. El Niño (La Niña) events deepen (shoal) the thermocline and intensify (weaken) the PCUC (e.g. Montes et al., 2011; Combes et al., 2015). Intraseasonal and interannual variability is another factor modulating the strength of the PCUC off Chile and therefore the formation rate of anticyclonic eddies (Shaffer et al., 1999).

In this study the development of isolated water mass properties was investigated on the basis of four floats trapped within an anticyclonic eddy indicating lateral mixing of all water properties (oxygen, temperature, and salinity). The water mass within the core of the ACE2 shows the typical characteristics of the salty and oxygen-depleted ESSW. The mixing is strongest between the seasonal thermocline and the core of the eddy at about $\sigma_{\theta}=26.3 \mathrm{~kg} \mathrm{~m}^{-3}$ ( $\sim 205$ to $240 \mathrm{~m}$ depth) and takes place during the first half of the lifetime of the eddy. During this period the variability in the amplitude of the ACE2 is negligibly small, which might be due to the coarse resolution of the satellite data. The radius increases up to $50 \mathrm{~km}$ with a nearly consistent rotation velocity at the same time (Fig. 5a, b). During the second half of the lifetime the radius of the ACE2 slightly increases but the maximum rotation velocity and therefore the nonlinear parameter decreases (Fig. 5c) until the decay of the ACE2. Stronger mixing during the first half of the eddy lifetime could be related to a stronger wind curl near the coast in comparison to the open ocean (Albert et al., 2010, their Fig. 1b). However, as the changes might also be due to the fact that the floats might be located at different positions within the eddy or near the outer edge these results should be regarded with caution. Often floats are carried with the eddies near the outer edge of the eddy, avoid the core of eddies, and hence underestimate the strength of eddies. Especially floats with a parking depth at $400 \mathrm{~m}$ stay near the edge of eddies and shift between cyclonic and anticyclonic features. If located in the ETSP at southern boundaries of anticyclones or northern boundaries of cyclones the floats move eastward while floats at northern boundaries of anticyclones or southern boundaries of cyclones move westward (see Supplement movie M1).

Eddies play an important role in the weak circulation region of the ETSP. Regarding the mean flow in the ETSP at 
the position of the Stratus mooring the zonal annual mean velocity components for the periods 2011/2012 and 2014/2015 as well as for the period October 2000 to December 2004 are quite different (between -4.6 and $+2.5 \mathrm{~cm} \mathrm{~s}^{-1}$ ), while the meridional components are generally weaker (between -2.1 and $2.3 \mathrm{~cm} \mathrm{~s}^{-1}$ ) and more similar (Supplement Fig. S4). In 2011/2012 the flow component is south-eastward between 100 and $450 \mathrm{~m}$ depth and in 2014/2015 south-westward in the upper $50 \mathrm{~m}$ depth, north-westward at 50 to $250 \mathrm{~m}$ depth, and mainly southward at 250 to $600 \mathrm{~m}$ depth. The northwestward flow at 50 to $250 \mathrm{~m}$ depth in 2014/2015 would fit to a mean South Pacific subtropical gyre circulation (e.g. Ayón et al., 2008); however, the period 2011/2012 showed mean eastward flow at all depths between 50 and $600 \mathrm{~m}$ and in the 2000/2004 period (Colbo and Weller, 2007) the eastward flow component at 45 to $235 \mathrm{~m}$ also showed the opposite flow component. Hence, the different measurement periods at the Stratus mooring do not support the view of a mean north-westward flow of the South Pacific subtropical gyre at the mooring location and other processes dominate the flow field.

Observations from the mooring deployment period March 2014 to April 2015 and profiling floats deployed near eddies in March 2014 (Fig. 1) show the importance of eddies in the weak flow region of the ETSP as mesoscale eddies play a crucial role in water mass distribution. High anomalies of heat, salt, and oxygen transported within eddies into the ETSP suggests the influence of seasonal and/or interannual variability in the formation regions off Peru and Chile.

It is necessary to further gain knowledge about the seasonal, interannual, and other variability having an impact on the generation of eddies and on the water mass properties that are trapped within eddies to understand their impact on the maintenance and shape of the OMZ. The most promising methods to tackle the open questions would be longterm measurements near the coast, glider measurements in the centre of the eddies, and accompanying model investigations.

Data availability. The used satellite data of SLA can be freely downloaded at Copernicus Marine and Environment Monitoring Service (CMEMS, 2018, http://marine.copernicus.eu). The Copernicus Marine and Environment Monitoring Service (CMEMS) (http://marine.copernicus.eu) has taken over the whole processing and distribution of the products formerly distributed by AVISO with no changes in the scientific content.

Microwave OI SST data are produced by Remote Sensing Systems and sponsored by National Oceanographic Partnership Program (NOPP) and the NASA Earth Science Physical Oceanography Program. Data are available at http://www.remss. com/measurements/sea-surface-temperature (last access: $17 \mathrm{Au}-$ gust 2017).

$\begin{array}{rlccc}\text { Chlorophyll data can be freely downloaded } \\ \text { at National } & \text { Aeronautics and } & \text { Space Administra- }\end{array}$

tion (NASA, 2018, http://oceancolor.gsfc.nasa.gov, https://doi.org/10.5067/AQUA/MODIS/L3M/CHL/2018).

Argo float data and Stratus Ocean Reference Station (ORS) data used in this paper are available at Pangaea (https://doi.pangaea.de/ 10.1594/PANGAEA.892463, Czeschel et al., 2018.).

Author contributions. RC, FS, and LS conceived the study. RC handled the float data. FS collected and interpreted the satellite data set. RAW is responsible for the Stratus ORS mooring measurements and the data processing. All authors discussed, wrote, and modified the manuscript.

Competing interests. The authors declare that they have no conflict of interest.

Acknowledgements. Financial support was received through Woods Hole Oceanographic Institution (Robert A. Weller) and the GEOMAR (Rena Czeschel, Lothar Stramma, and Florian Schütte). The Stratus Ocean Reference Station is supported by the National Oceanic and Atmospheric Administration (NOAA) Climate Observation Program (NA09AR4320129, OAA CPO FundRef number 100007298). This work is a contribution of the Deutsche Forschungsgemeinschaft (DFG) supported project "Sonderforschungsbereich 754: Climate-Biogeochemistry Interactions in the Tropical Ocean" (http://www.sfb754.de, last access: 27 June 2018).

Edited by: Matthew Hecht

Reviewed by: two anonymous referees

\section{References}

Albert, A., Echevin, V., Lévy, M., and Aumont, O.: Impact of nearshore wind stress curl on coastal circulation and primary productivity in the Peru upwelling system, J. Geophys. Res., 115, C12033, https://doi.org/10.1029/2010JC006569, 2010.

Altabet, M. A., Ryabenko, E., Stramma, L., Wallace, D. W. R., Frank, M., Grasse, P., and Lavik, G.: An eddy-stimulated hotspot for fixed nitrogen-loss from the Peru oxygen minimum zone, Biogeosciences, 9, 4897-4908, https://doi.org/10.5194/bg9-4897-2012, 2012. .

Ayón, P., Criales-Hernandez, M. I., Schwamborn, P., and Hirche, H.-J.: Zooplankton research off Peru: A review, Prog. Oceanogr., 79, 238-255, https://doi.org/10.1016/j.pocean.2008.10.020, 2008.

Brandt, P., Bange, H. W., Banyte, D., Dengler, M., Didwischus, S.-H., Fischer, T., Greatbatch, R. J., Hahn, J., Kanzow, T., Karstensen, J., Körtzinger, A., Krahmann, G., Schmidtko, S., Stramma, L., Tanhua, T., and Visbeck, M.: On the role of circulation and mixing in the ventilation of oxygen minimum zones with a focus on the eastern tropical North Atlantic, Biogeosciences, 12, 489-512, https://doi.org/10.5194/bg-12-489-2015, 2015.

Callbeck, C. M., Lavik, G., Stramma, L., Kuypers, M. M. M., and Bristow, L. A.: Enhanced nitrogen loss by 
eddy-induced vertical transport in the offshore Peruvian oxygen minimum zone, PLoS ONE, 12, e0170059, https://doi.org/10.1371/journal.pone.0170059, 2017.

Capet, X., McWilliams, J. C., Molemaker, M. J., and Shchepetkin, A. F.: Mesoscale to submesoscale transition in the California current system. Part II: Frontal processes, J. Phys. Oceanogr., 38, 44-64, 2008.

Chaigneau, A., Gizolme, A., and Grados, C.: Mesoscale eddies off Peru in altimeter records: Identification algorithms and eddy spatiotemporal patterns, Prog. Oceanogr., 79, 106-119, 2008.

Chaigneau, A., Le Texier, M., Eldin, G., Grados, C., and Pizarro, O.: Vertical structure of mesoscale eddies in the eastern South Pacific Ocean: A composite analysis from altimetry and Argo profiling floats, J. Geophys. Res., 116, C11025, https://doi.org/10.1029/2011JC007134, 2011.

Chaigneau, A., Dominguez, N., Eldin, G., Vasquez, I., Flores, R., Grados, C., and Echevin, V.: Near-coastal circulation in the northern Humboldt Current system from shipboard ADCP data, J. Geophys. Res., 118, 5251-5266, https://doi.org/10.1002/jgrc.20328, 2013.

Chelton, D. B., Schlax, M. G., Samelson, R. M., and de Szoeke, R. A.: Global observations of large oceanic eddies, Geophys. Res. Lett., 34, L15606, https://doi.org/10.1029/2007GL030812, 2007.

Chelton, D. B., Gaube, P., Schlax, M. G., Early, J. J., and Samelson, R. M.: The influence of nonlinear mesoscale eddies on near-surface oceanic chlorophyll, Science, 334, 328-332, https://doi.org/10.1126/science.1208897, 2011.

CMEMS: Copernicus Marine and Environment Monitoring Service, Sea Level Anomaly, available at: http://marine.copernicus. eu, last access: 6 February 2018.

Colbo, K. and Weller, R.: The variability and heat budget of the upper ocean under the Chile-Peru stratus, J. Mar. Res., 65, 607637, 2007.

Colbo, K. and Weller, R.: Accuracy of the IMET sensor package in the subtropics, J. Atmos. Oceanic Technol., 26, 1867-1890, https://doi.org/10.1175/2009JTECHO667.1, 2009.

Combes, V., Hormazabal, S., and Di Lorenzo, E.: Interannual variability of the subsurface eddy field in the Southeast Pacific, J. Geophys. Res.-Oceans, 120, 4907-4924, https://doi.org/10.1002/2014JC010265, 2015.

Czeschel, R., Stramma, L., Schwarzkopf, F. U., Giese, B. J., Funk, A., and Karstensen, J.: Middepth circulation of the eastern tropical South Pacific and its link to the oxygen minimum zone, J. Geophys. Res., 116, C01015, https://doi.org/10.1029/2010JC006565, 2011.

Czeschel, R., Stramma, L., Weller, R. A., and Fischer, T.: Circulation, eddies, oxygen, and nutrient changes in the eastern tropical South Pacific Ocean, Ocean Sci., 11, 455-470, https://doi.org/10.5194/os-11-455-2015, 2015.

Czeschel, R., Schütte, F., Weller, R. A., and Stramma, L.: Transport, properties and life cycles of mesoscale eddies in the eastern tropical South Pacific, available at: https://doi.pangaea.de/10.1594/ PANGAEA.892463 (last access: 25 July 2018), 2018

D'Asaro, E. A.: Generation of submesoscale vortices - a new mechanism, J. Geophys. Res.-Oceans, 93, 6685-6693, 1988.

Dalsgaard, T., Thamdrup, B., Farías, L., and Revsbech, N. P.: Anammox and denitrification in the oxygen minimum zone of the eastern South Pacific, Limnol. Oceanogr., 57, 1331-1346, 2012 .
Fiedler, B., Grundle, D. S., Schütte, F., Karstensen, J., Löscher, C. R., Hauss, H., Wagner, H., Loginova, A., Kiko, R., Silva, P., Tanhua, T., and Körtzinger, A.: Oxygen utilization and downward carbon flux in an oxygen-depleted eddy in the eastern tropical North Atlantic, Biogeosciences, 13, 5633-5647, https://doi.org/10.5194/bg-13-5633-2016, 2016.

Frenger, I., Münnich, M., Gruber, N., and Knutti, R.: Phenomenology of Southern Ocean eddies, J. Geophys. Res.-Oceans, 120, 7413-7449, https://doi.org/10.1002/2015JC011047, 2015.

Frenger, I., Bianchi, D., Stührenberg, C., Oschlies, A., Dunne, J., Deutsch, C., Galbraith, E., and Schütte, F.: Biogeochemical role of subsurface coherent eddies in the ocean: Tracer cannonballs, hypoxic storms, and microbial stewpots?, Global Biogeochem. Cy., 32, 226-249, https://doi.org/10.1002/2017GB005743, 2018.

Gaube, P., Chelton, D. B., Strutton, P. G., and Behrenfeld, M. J.: Satellite observations of chlorophyll, phytoplankton biomass, and Ekman pumping in nonlinear mesoscale eddies, J. Geophys. Res.-Oceans, 118, 6349-6370, https://doi.org/10.1002/2013JC009027, 2013.

Gaube, P., Chelton, D. B., Samelson, R. M., Schlax, M. G., and O'Neill, L. W.: Satellite observations of mesoscale eddyinduced Ekman pumping, J. Phys. Oceanogr., 45, 104-132, https://doi.org/10.1175/JPO-D-14-0032.1, 2015.

Gunther, E. R.: A report on oceanographic investigations in the Peru Coastal Current, Discovery Reports, 13, 107-276, 1936.

Gutiérrez, D., Bouloubassi, I., Sifeddine, A., Purca, S., Goubanova, K., Graco, M., Field, D., Méjanelle, L., Velazco, F., Lorre, A., Salvatteci, R., Quispe, D., Vargas, G., Dewitte, B., and Ortlieb, L., : Coastal cooling and increased productivity in the main upwelling zone off Peru since the mid-twentieth century, Geophys. Res. Lett., 38, L07603, https://doi.org/10.1029/2010GL046324, 2011.

Hauss, H., Christiansen, S., Schütte, F., Kiko, R., Edvam Lima, M., Rodrigues, E., Karstensen, J., Löscher, C. R., Körtzinger, A., and Fiedler, B.: Dead zone or oasis in the open ocean? Zooplankton distribution and migration in low-oxygen modewater eddies, Biogeosciences, 13, 1977-1989, https://doi.org/10.5194/bg-131977-2016, 2016.

Holte, J., Straneo, F., Moffat, C., Weller, R., and Farrar, J. T.: Structure and surface properties of eddies in the southeast Pacific Ocean, J. Geophys. Res.-Oceans, 118, 1-15, https://doi.org/10.1002/jgrc.20175, 2013.

Hormazabal, S., Combes, V., Morales, C. E., Correa-Ramirez, M., Di Lorenzo, E., and Nunez, S.: Intrathermocline eddies in the coastal transition zone off central Chile $\left(31-41^{\circ} \mathrm{S}\right)$, J. Geophys. Res., 118, 1-11. https://doi.org/10.1002/jgrc.20337, 2013.

Huyer, A., Knoll, M., Paluszkiewicz, T., and Smith, R. L.: The Peru Undercurrent: a study in variability, Deep Sea Res. Pt. A, 38(suppl. 1), 247-279, 1991.

Johnson, G. C., Schmidtko, S., and Lyman, J. M.: Relative contributions of temperature and salinity to seasonal mixed layer density changes and late-winter horizontal density gradients, J. Geophys. Res., 117, C04015, https://doi.org/10.1029/2011JC007651, 2012.

Karstensen, J., Stramma, L., and Visbeck, M.: Oxygen minimum zones in the eastern tropical Atlantic and Pacific oceans, Prog. Oceanogr., 77, 331-350, 2008.

Karstensen, J., Fiedler, B., Schütte, F., Brandt, P., Körtzinger, A., Fischer, G., Zantopp, R., Hahn, J., Visbeck, M., and Wallace, 
D.: Open ocean dead zones in the tropical North Atlantic Ocean, Biogeosciences, 12, 2597-2605, https://doi.org/10.5194/bg-122597-2015, 2015.

Karstensen, J., Schütte, F., Pietri, A., Krahmann, G., Fiedler, B., Grundle, D., Hauss, H., Körtzinger, A., Löscher, C. R., Testor, P., Vieira, N., and Visbeck, M.: Upwelling and isolation in oxygen-depleted anticyclonic modewater eddies and implications for nitrate cycling, Biogeosciences, 14, 2167-2181, https://doi.org/10.5194/bg-14-2167-2017, 2017.

Kessler, W. S.: The circulation of the eastern tropical Pacific: a review, Prog. Oceanogr., 89, 181-217, https://doi.org/10.1016/j.pocean.2006.03.009, 2006.

Klein, P. and Lapeyre, G: The oceanic vertical pump induced by mesoscale and submesoscale turbulence, Annu. Rev. Mar. Sci, 1, 351-373, 2009.

Kurian, J., Colas, F., Capet, X., McWilliams, J. C., and Chelton, D. B.: Eddy properties in the California Current system, J. Geophys. Res., 116, C08027, doi10.1029/2010JC006895, 2011.

Liu, Y., Dong, C., Guan, Y., Chen, D., McWilliams, J., and Nencioli, F.: Eddy analysis in the subtropical zonal band of the North Pacific Ocean, Deep-Sea Res. Pt. I., 68, 54-67, 2012.

Llanillo, P. J., Pelegrí, J. L., Talley, L. D., Peña-Izquierdo, J., and Cordero, R. R.: Oxygen pathways and budgets for the eastern South Pacific oxygen minimum zone, J. Geophys. Res., 123, 1722-1744, https://doi.org/10.1002/2017JC013509, 2018.

Löscher, C. R., Fischer, M. A., Neulinger, S. C., Fiedler, B., Philippi, M., Schütte, F., Singh, A., Hauss, H., Karstensen, J., Körtzinger, A., Künzel, S., and Schmitz, R. A.: Hidden biosphere in an oxygen-deficient Atlantic open-ocean eddy: future implications of ocean deoxygenation on primary production in the eastern tropical North Atlantic, Biogeosciences, 12, 7467-7482, https://doi.org/10.5194/bg-12-7467-2015, 2015.

Lukas, R. and Santiago-Mandujano, F.: Extreme water mass anomaly observed in the Hawaii ocean time-series, Geophys. Res. Lett., 28, 2931-2934, https://doi.org/10.1029/2001GL013099, 2001.

McGillicuddy Jr., D. J.: Formation of intrathermocline lenses by eddy-wind Interaction, J. Phys. Oceanogr., 45, 606-612, https://doi.org/10.1175/JPO-D-14-0221.1, 2015.

McGillicuddy Jr., D. J., Anderson, L. A., Bates, N. R., Bibby, T., Buesseler, K. O., Carlson, C. A., Davis, C. S., Ewart, C., Falkowski, P. G., Goldthwait, S. A., Hansell, D. A., Jenkins, W. J., Johnson, R., Kosnyrev, V. K., Ledwell, J. R., Li, Q. P., Siegel, D. A., and Steinberg, D. K.: Eddy/wind interactions stimulate extraordinary mid-ocean plankton blooms, Science, 316, 10211026, 2007.

McWilliams, J. C.: Submesoscale, coherent vortices in the ocean, Rev. Geophys., 23, 165-182, https://doi.org/10.1029/RG023i002p00165, 1985.

McWilliams, J. C., Colas, F., and Molemaker, M. J.: Cold filamentary intensification and oceanic surface convergence lines, Geophys. Res. Lett., 36, L18602, https://doi.org/10.1029/2009GL039402, 2009.

Molemaker, M. J., McWilliams, J. C., and Dewar, W. K.: Submesoscale instability and generation of mesoscale anticyclones near a separation of the California undercurrent, J. Phys. Oceanogr., 45, 613-629, https://doi.org/10.1175/JPO-D-13-0225.1, 2015.

Montes, I., Schneider, W., Colas, F., Blanke, B., and Echevin, V.: Subsurface connections in the eastern tropical Pacific during $\mathrm{La}$
Niña 1999-2001 and El Niño 2002-2003, J. Geophys. Res., 116, C12022, https://doi.org/10.1029/2011JC007624, 2011.

Montes, I., Dewitte, B., Gutknecht, E., Paulmier, A., Dadou, I., Oschlies, A., and Garçon, V.: High-resolution modeling of the Eastern Tropical Pacific oxygen minimum zone: Sensitivity to the tropical oceanic circulation, J. Geophys. Res.-Oceans, 119, 5515-5532, https://doi.org/10.1002/2014JC009858, 2014.

NASA Goddard Space Flight Center (Ocean Ecology Laboratory, Ocean Biology Processing Group): Moderate-resolution Imaging Spectroradiometer (MODIS) Aqua Chlorophyll Data; 2018 Reprocessing, NASA OB.DAAC, Greenbelt, MD, USA, https://doi.org/10.5067/AQUA/MODIS/L3M/CHL/2018, last access: 18 June 2018.

Nencioli, F., Dong, C., Dickey, T., Washburn, L., and McWilliams, J. C.: A vector geometry based eddy detection algorithm and its application to a high-resolution numerical model product and high-frequency radar surface velocities in the southern California bight, J. Atmos. Ocean. Tech., 27, 564-579, 2010.

Paulmier, A. and Ruiz-Pino, D.: Oxygen minimum zones (OMZs) in the modern ocean, Prog. Oceanogr., 80, 113-128, https://doi.org/10.1016/j.pocean.2008.08.001, 2009.

Pegliasco, C., Chaigneau, A., and Morrow, R.: Main eddy vertical structures observed in the four major Eastern Boundary Upwelling Systems, J. Geophys. Res.-Oceans, 120, 6008-6033, https://doi.org/10.1002/2015JC010950, 2015.

Penven, P., Echevin, V., Paspera, J., Colas, F., and Tam, J.: Average circulation, seasonal cycle, and mesoscale dynamics of the Peru Current system: A modeling approach, J. Geophys. Res., 110, C10021, https://doi.org/10.1029/2005JC002945, 2005.

REMSS: Remote Sensing Systems, Microwave-Infrared optimal interpolated Sea Surface Temperature, available at: http://www. remss.com, last access: 17 August 2017.

Samelson, R. M., Schlax, M. G., and Chelton, D. B.: Randomness, Symmetry, and Scaling of Mesoscale Eddy Life Cycles, J. Phys. Oceanogr., 44, 1012-1029, https://doi.org/10.1175/JPOD-13-0161.1, 2014.

Schmidtko, S., Johnson, G. C., and Lyman, J. M.: MIMOC: A Global Monthly Isopycnal Upper-Ocean Climatology with Mixed Layers, J. Geophys. Res., 118, 1658-1672, https://doi.org/10.1002/jgrc.20122, 2013.

Schütte, F., Brandt, P., and Karstensen, J.: Occurrence and characteristics of mesoscale eddies in the tropical northeastern Atlantic Ocean, Ocean Sci., 12, 663-685, https://doi.org/10.5194/os-12663-2016, 2016a.

Schütte, F., Karstensen, J., Krahmann, G., Hauss, H., Fiedler, B., Brandt, P., Visbeck, M., and Körtzinger, A.: Characterization of "dead-zone" eddies in the eastern tropical North Atlantic, Biogeosciences, 13, 5865-5881, https://doi.org/10.5194/bg-135865-2016, 2016b.

Shaffer, G., Hormazabal, S., Pizarro, O., and Salinas, S.: Seasonal and interannual variability of winds, current and temperature near the coast of Chile, J. Geophys. Res., 104, 29951-29961, 1999.

Stramma, L., Johnson, G. C., Firing, E., and Schmidtko, S.: Eastern Pacific oxygen minimum zones: Supply paths and multidecadal changes, J. Geophys. Res., 115, C09011, https://doi.org/10.1029/2009JC005976, 2010.

Stramma, L., Bange, H. W., Czeschel, R., Lorenzo, A., and Frank, M.: On the role of mesoscale eddies for the biolog- 
ical productivity and biogeochemistry in the eastern tropical Pacific Ocean off Peru, Biogeosciences, 10, 7293-7306, https://doi.org/10.5194/bg-10-7293-2013, 2013.

Stramma, L., Weller, R. A., Czeschel, R., and Bigorre, S.: Eddies and an extreme water mass anomaly observed in the eastern south Pacific at the Stratus mooring, J. Geophys. Res.-Oceans, 119, 1068-1083, https://doi.org/10.1002/2013JC009470, 2014.

Stramma, L., Fischer, T., Grundle, D. S., Krahmann, G., Bange, H. W., and Marandino, C. A.: Observed El Niño conditions in the eastern tropical Pacific in October 2015, Ocean Sci., 12, 861873, https://doi.org/10.5194/os-12-861-2016, 2016.

Thomsen, S., Kanzow, T., Krahmann, G., Greatbatch, R. J., Dengler, M., and Lavik, G.: The formation of a subsurface anticyclonic eddy in the Peru-Chile Undercurrent and its impact on the near-coastal salinity, oxygen, and nutrient distributions, J. Geophys. Res.-Oceans, 121, 476-501, https://doi.org/10.1002/2015JC010878, 2016.
Tsuchiya, M. and Talley, L. D.: A Pacific hydrographic section at $88^{\circ} \mathrm{W}$ : Water-property distribution, J. Geophys. Res., 103, 12899-12918, 1998.

Vergara, O., Dewitte, B., Montes, I., Garçon, V., Ramos, M., Paulmier, A., and Pizarro, O.: Seasonal variability of the oxygen minimum zone off Peru in a high-resolution regional coupled model, Biogeosciences, 13, 4389-4410, https://doi.org/10.5194/bg-134389-2016, 2016.

Zhang, Z., Zhang, Y., and Wang, W.: Three-compartment structure of subsurface-intensified mesoscale eddies in the ocean, J. Geophys. Res.-Oceans, 122, 1653-1664, https://doi.org/10.1002/2016JC012376, 2017. 